\title{
Measurement of size-dependent single scattering albedo of fresh biomass burning aerosols using the extinction-minus-scattering technique with a combination of cavity ring-down spectroscopy and nephelometry
}

\author{
Sujeeta Singh ${ }^{1}$, Marc N. Fiddler ${ }^{2}$, and Solomon Bililign ${ }^{2,3}$ \\ ${ }^{1}$ Energy and Environmental Systems Department, North Carolina A\&T State University, Greensboro, North Carolina, USA \\ ${ }^{2}$ Department of Physics, North Carolina A\&T State University, Greensboro, North Carolina, USA \\ ${ }^{3}$ NOAA-ISET Center, North Carolina A\&T State University, Greensboro, North Carolina, USA
}

Correspondence to: Solomon Bililign (bililignsol@gmail.com)

Received: 9 April 2016 - Published in Atmos. Chem. Phys. Discuss.: 13 June 2016

Revised: 21 August 2016 - Accepted: 11 October 2016 - Published: 1 November 2016

\begin{abstract}
Biomass burning (BB) aerosols have a significant effect on regional climate, and represent a significant uncertainty in our understanding of climate change. Using a combination of cavity ring-down spectroscopy and integrating nephelometry, the single scattering albedo (SSA) and Angstrom absorption exponent (AAE) were measured for several North American biomass fuels. This was done for several particle diameters for the smoldering and flaming stage of white pine, red oak, and cedar combustion. Measurements were done over a wider wavelength range than any previous direct measurement of BB particles. While the offline sampling system used in this work shows promise, some changes in particle size distribution were observed, and a thorough evaluation of this method is required. The uncertainty of SSA was $6 \%$, with the truncation angle correction of the nephelometer being the largest contributor to error. While scattering and extinction did show wavelength dependence, SSA did not. SSA values ranged from 0.46 to 0.74 , and were not uniformly greater for the smoldering stage than the flaming stage. SSA values changed with particle size, and not systematically so, suggesting the proportion of tar balls to fractal black carbon change with fuel type/state and particle size. SSA differences of $0.15-0.4$ or greater can be attributed to fuel type or fuel state for fresh soot. AAE values were quite high (1.59-5.57), despite SSA being lower than is typically observed in wildfires. The SSA and AAE values in this work do not fit well with current schemes that relate these factors to the modified combustion efficiency of a burn.
\end{abstract}

Combustion stage, particle size, fuel type, and fuel condition were found to have the most significant effects on the intrinsic optical properties of fresh soot, though additional factors influence aged soot.

\section{Introduction}

Biomass burning (BB) is recognized as one of the largest sources of absorbing aerosols in the atmosphere (Bond et al., 2013; Jacobson, 2014; Ramanathan and Carmichael, 2008; Moosmüller et al., 2009). Smoke from BB is composed of gaseous and aerosol constituents, including black carbon (BC), brown carbon (BrC), organic carbon (OC), and mineral dust, all of which have critical climate and health impacts. Global climate impacts of BB result from its truly massive contributions to aerosol optical depth over large areas and from secondary processes, such as cloud and ice nucleation, which can increase the radiative impact of the emissions. BB aerosols have significant impacts, not only on local climate, but also on regional climate, air quality, and hydrological cycles (Alonso-Blanco et al., 2014; Haywood et al., 2003, 2008; Fu et al., 2012; Lin et al., 2013; Yen et al., 2013; Reid et al., 2005, 2013).

With an estimated total climate forcing of $+1.1 \mathrm{~W} \mathrm{~m}^{-2}$, $\mathrm{BC}$ is the second most important emission for humans in terms of its climate forcing in the present-day atmosphere, 
second to $\mathrm{CO}_{2}$ (Bond et al., 2013). The impacts of wildfires are mostly associated with short-term climate forcers, such as ozone and aerosols. Depending on surface albedo and the relative amounts of $\mathrm{OC}$ and $\mathrm{BC} / \mathrm{BrC}, \mathrm{BB}$ smoke can heat or cool the atmosphere, provide condensation nuclei for ice and water reduce visibility, and affect air quality. The recent estimate (IPCC, 2013) of biomass aerosol radiative forcing is $50 \%$ larger than earlier estimates.

In the atmosphere, aerosols dynamically change in complex ways. BC is initially produced during the combustion of carbon-based fuels when oxygen is insufficient for complete combustion during BB (Bond et al., 2013; Bond and Bergstrom, 2006). The chemical composition and physical properties of particles then evolve during their atmospheric lifetime due to condensation, oxidation reactions, etc. Soot is formed from organic precursors in high temperatures and insufficient oxygen environments where volatiles and primary tars react to form secondary tars to form polyaromatic hydrocarbons (PAH), which subsequently form soot particles by further agglomeration and release of hydrogen (Nussbaumer, 2010).

A theoretical $\mathrm{BC}$ aging model was developed to account for three major stages of aging: aggregates of graphitic spheres and primary tars freshly emitted from BB, aggregates becoming coated with condensable material, and $\mathrm{BC}$ particles undergoing further hygroscopic growth (He et al., 2015). $\mathrm{BB}$ aerosols are subject to extensive chemical processing in the atmosphere as they are exposed to sunlight, other pollutants like biogenic volatile organic compounds (VOCs), and oxidants such as ozone $\left(\mathrm{O}_{3}\right)$, hydroxyl radical $(\mathrm{OH})$, and $\mathrm{NO}_{x}\left(\mathrm{NO}+\mathrm{NO}_{2}\right)$. The timescale for these processes is quite short, on the order of a few minutes to hours (Hennigan et al., 2011; Rudich et al., 2007; Saleh et al., 2013; Hemminger, 1999; Haan et al., 1999; Cubison et al., 2011; Vakkari et al., 2014). Additionally, there is evidence of both loss and gain of particle mass, and rapid atmospheric oxidation (Vakkari et al., 2014). While semivolatile compounds condense when they are cooled, as smoke is diluted, these compounds can revolatilize, which reduces aerosol mass (Robinson et al., 2007).

As these physical and chemical changes take place, the optical properties of these particles are also altered. Variations in optical properties of soot particles due to internal mixing in the atmosphere and aging remain highly uncertain, hindering efforts to assess their impact on climate. Understanding the effect of aging on composition and the commensurate optical property changes remains a challenge. Theoretical calculations are consistent with measurements in extinction and absorption cross sections for fresh BC aggregates, but overestimate the scattering cross sections for BC with mobility diameters below $\sim 350 \mathrm{~nm}$, because of uncertainties associated with theoretical calculations and laboratory scattering measurements for small particles (He et al., 2015). The increase in $\mathrm{BC}$ scattering during aging was much stronger than absorption, ranging from a factor of 3 to 24 depending on $\mathrm{BC}$ size, morphology, and aging stage (He et al., 2015). Clearly, a proper description of optical properties of particles (along with fuel inventories, emission factors, remote observations, etc.) is essential for analyzing and predicting the climate impacts of BB.

These radiative balance calculations require knowledge of aerosol optical properties, including single scattering albedo (SSA), scattering and absorption cross sections and efficiencies, and Ångstrom coefficients. SSA, in particular, is crucial for predicting the direct radiative forcing of an aerosol. A number of experimental techniques have been used to measure the optical properties of BB aerosols (Bond et al., 1999; Holben et al., 1998; Arnott et al., 1999, 2003; Haywood et al., 2003; Clarke et al., 2004; Petzold and Schonlinner, 2004; Schnaiter et al., 2005b; Lack et al., 2006; Moosmüller et al., 2009). By combining photoacoustic spectroscopy (PAS) with nephelometry, one can simultaneously measure both absorption and scattering (Chakrabarty et al., 2014; Nakayama et al., 2013; Lewis et al., 2008; Gyawali et al., 2012; Flowers et al., 2010; Wang et al., 2014). Massoli et al. (2009) examined the uncertainty in the SSA of absorbing particles, based on measurements that combine cavity ring-down spectroscopy (CRDS) for extinction measurements with either nephelometry for scattering or PAS for absorption. Uncertainties in SSA using nephelometer data are larger and are most significant for SSA $<0.7$ (Massoli et al., 2009). Massoli et al. (2009) observed nephelometer scattering cross section errors using the Anderson and Ogren correction method to be $3 \%$ at SSA $=1$, increasing to $5 \%$ at SSA $=0.7$, and $29 \%$ at SSA $=0.4$ (Fig. 7. in their work). This is the main contributor SSA error, which is $30 \%$ at SSA $=0.4$. They reduced this to $25 \%$ using an alternative scheme for deriving a correction for the instruments inability to measure high and low scattering angles $(C(\lambda))$, but the CRDS/PAS combination yielded SSA errors of between $<1 \%$ at SSA $=1$ and $8 \%$ at SSA $=0.4$. (Massoli et al., 2009). This will be a significant source of error for measurement environments of fresh biomass burning plumes. In comparison, they report an uncertainty of $<2 \%$ for this same range when photoacoustic absorption measurements are combined with CRDS (Massoli et al., 2009).

A sensitive technique for measurement of SSA is the combination of CRDS to measure extinction (scattering + absorption) and integrating nephelometry to measure scattering. CRDS promises aerosol extinction measurements with accuracies of $2 \%$ or better (Smith and Atkinson, 2001; Strawa et al., 2003; Pettersson et al., 2004), and the integrating nephelometer has a reported accuracy of $\sim 7 \%$ (Anderson and Ogren, 1998). The extinction and the scattering coefficients are measured simultaneously for the same aerosol sample in this system, though we are not sampling the same space in this work. The extinction-minus-scattering technique has been used for airborne ambient measurements (Hallar et al., 2006), for studies involving optical properties of biomass aerosols and humic-like aerosols using CRD for measurement of extinction and Mie theory calculations to de- 
termine scattering and absorption (Abo Riziq et al., 2007, 2008; Dinar et al., 2008), and for studies determining the extinction of isolated aerosol particles (Butler et al., 2007; Miller and Orr-Ewing, 2007). In our recent calibration study (Singh et al., 2014) we have accounted for errors due to differences in particle concentration between the condensation particle counter (CPC), nephelometer, and CRDS. Instead of using absolute concentration values, the number-density ratio between the CRDS and nephelometer, based on loss measurements, was used to derive SSA. We found that this is the only method in which SSA values are at all useful, which is $1.7-4.3 \%$ (2.1\% average) for particles $\geq 200 \mathrm{~nm}$ in diameter, as opposed to $\sim 14.3 \%$ for other methods. The run-to-run variability of SSA measurements is $\sim 2 \%$. At 2 standard deviations, SSA values of $\leq 0.91$ can safely be determined using this technique, with $\leq 0.96$ achievable on average. That is, this is the SSA value where CRDS and nephelometer values can be statistically differentiated at 2 standard deviations.

In this article, we report extinction, scattering, absorption, and SSA measurement results of freshly emitted soot aerosols impinged in distilled water from burning white oak, red pine, and cedar wood. Our main goal is to obtain a base line (i.e., fresh soot) to compare these same properties measured as aerosols' age. Most current measurements are limited to a single or few discrete wavelengths. The accurate measurement of aerosol optical properties over the entire solar spectrum is currently a technological challenge ( $\mathrm{Ra}-$ manathan and Carmichael, 2008). Accurate and realistic interpretation of aerosol radiative properties obtained by remote sensing and space-based measurements requires accurate measurements of the optical properties of aerosols in the laboratory. Featured absorption cross sections need to be determined, instead of assuming a power law relationship, which requires more effort and advanced instrumentation than single wavelength measurements. We report measurements of optical properties at a wide range of wavelengths to determine absorption cross sections as a function of wavelength which does not rely on any power law relationship.

\section{Experimental methods}

\subsection{Cavity ring-down setup}

Details of the experimental method and derivation of key equations for particle optical properties and CRDS analysis have been described (Singh et al., 2014, and references therein). We only summarize the main points, and we encourage the reader to see the reference cited for details. The key equation for CRD measurement is the extinction coefficient $\alpha_{\text {ext }}\left(\mathrm{m}^{-1}\right)$, defined by

$\alpha_{\mathrm{ext}}=\frac{R_{\mathrm{L}}}{c_{\mathrm{air}}}\left(\frac{1}{\tau}-\frac{1}{\tau_{0}}\right)=\sigma_{\mathrm{ext}} N_{\mathrm{CRD}}$

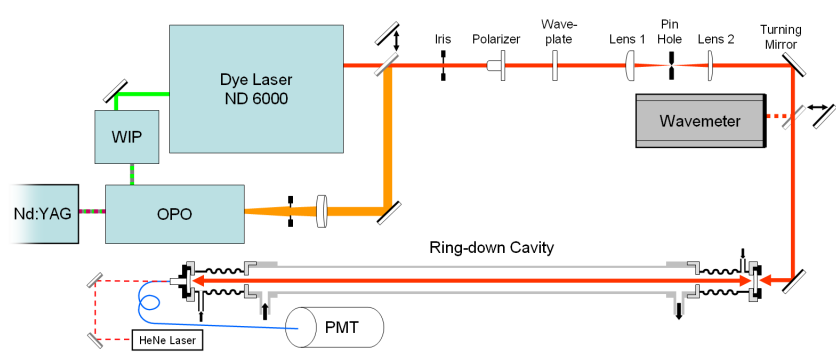

Figure 1. The laser and optical components of the CRDS instrument.

where $c_{\text {air }}$ is the speed of light in air, and $R_{\mathrm{L}}$ is the ratio of mirror-to-mirror distance $d$ to the length of the cavity occupied by the sample, resulting in a unitless value $>1$. The ringdown time is $\tau_{0}$ for an empty cavity and $\tau$ in the presence of a sample. Extinction coefficient is the product of the cross section $\sigma_{\text {ext }}\left(\mathrm{m}^{2}\right.$ particle $\left.{ }^{-1}\right)$ and number density of particles $N_{\text {CRD }}$ (particles $\mathrm{cm}^{-3}$ ) in the CRD cavity. A unit conversion factor has been omitted for simplicity.

The laser components of the system, shown in Fig. 1, included a Continuum Surelite I-20 Nd:YAG laser running at $20 \mathrm{~Hz}$. The $532 \mathrm{~nm}$ beam pumped a single grating ND6000 dye laser with a bandwidth of $0.08 \mathrm{~cm}^{-1}$ at $560 \mathrm{~nm}$, and the $355 \mathrm{~nm}$ beam pumped an optical parametric oscillator (OPO) laser. The OPO laser was also coupled to the ring-down cavity, which allowed a wider wavelength range than can be achieved with the dye laser, though with decreased beam quality. To retain most of the light exiting the OPO, the beam needed to be reshaped with $f=40 \mathrm{~cm}$ achromatic lens and an iris. The OPO had a relatively collimated beam $\sim 1 \mathrm{~cm}$ in diameter, and its bandwidth was $\sim 0.9 \mathrm{~nm}$ in the vicinity of $550 \mathrm{~nm}$ light, $\sim 2$ around $600 \mathrm{~nm}$, and $\sim 9$ at $660 \mathrm{~nm}$. This type of OPO had a bandwidth that increases asymptotically as it approached $710 \mathrm{~nm}$ (twice the $355 \mathrm{~nm}$ pump), so the dye laser was used in this region and the OPO was used at shorter wavelengths. For this work only the OPO was used. A polarizer and $\lambda / 4$ wave plate were used to isolate the lasers, and a telescope was used to mode-match the laser with the cavity. Since the mirrors were reflective over a limited wavelength range, several sets of mirrors were used to cover a wide wavelength range.

The CRDS system was controlled by a combination of commercial (Continuum) and home-built software. The ringdown measurements were recorded and analyzed in LabVIEW (National Instruments, version 8.6). The exponential decay was plotted in a log format and a line was fit between two cursors to determine the slope and, therefore, $\tau$. The laser wavelength was also controlled through LabVIEW, where the calibration of the laser wavelength was handled in LabVIEW for the dye laser and internally in the Continuum control software for the OPO. The dye laser was calibrated against a wave meter (Bristol Instruments, model 821B-Vis) over a range of wavelengths. WCPC (water-based CPC) mea- 


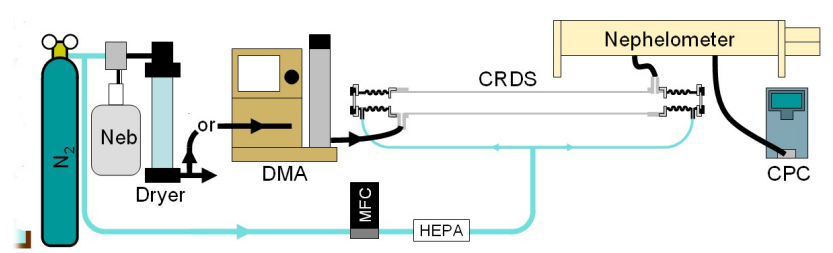

Figure 2. The integrated aerosol optical property measurement system.

surements used Aerosol Instrument Manager (TSI), and the nephelometer used NephWin (TSI) software.

\subsection{Aerosol generation system}

The aerosol processing and CRDS setup was similar to the one described by Spindler et al. (2007), with the only difference being the use of a single CPC and the use of both an OPO and a dye laser as light sources. A coupled differential mobility analyzer (DMA)-CPC (i.e., a scanning mobility particle sizer; SMPS) was used to determine the size distribution of aerosols. The current experimental setup is described below and shown in Fig. 2. A constant output nebulizer (TSI, model 3076 , modified) in recirculation mode was used to generate aerosols from an aqueous solution of suspended particles. This nebulizer was operated by supplying $35 \mathrm{psi}$ of filtered $\mathrm{N}_{2}$. This was fed into a diffusion drier (TSI, model 3062) to remove most of the water. The flow from the nebulizer was quite high $\left(3.2 \mathrm{sL} \mathrm{min}^{-1}\right)$, which necessitated splitting before the particle flow entered the DMA. Flow from the nebulizer entered the $710 \mu \mathrm{m}$ impactor inlet, neutralizer, and long DMA that contained a model 3080 (TSI) electrostatic classifier, where the aerosol was size-selected. Flow through the entire system $\left(0.58 \mathrm{sL} \mathrm{min}^{-1}\right)$ was produced by a pump within the CPC and the DMA sheath flow as $6.0 \mathrm{~L} \mathrm{~min}^{-1}$ in single blower mode. Aerosol flow then entered a ring-down cavity ( $170 \mathrm{~cm}$ long, stainless steel, $0.5 \mathrm{in}$. outer diameter), where the aerosol extinction was measured over a range of wavelengths. Aerosol scattering coefficients were then measured at 453,554 , and $698 \mathrm{~nm}$ using the integrating nephelometer (TSI, model 3563), and particle concentration was measured by the WCPC (TSI, model 3788). A purge flow was applied to custom mirror mounts (NOAA-ESRL) at both ends of the CRD cavity to maintain mirror reflectivity.

This gas passed from the $\mathrm{N}_{2}$ cylinder to a mass flow controller (MFC, Sierra Instruments, $20 \mathrm{~mL} \mathrm{~min}^{-1}$ ), and was cleaned using an inline HEPA filter (TSI, model 1602051) before the flow was split evenly between purge mirrors. Aerosols were passed through stainless steel fittings (Swagelok) and conductive graphite-impregnated silicone (TSI). All tubing and instruments were connected physically and electrically, and placed at ground potential to maximize the transmission of charged aerosols though the system. All flows, except the DMA sheath flow, were calibrated against a NIST-certified flow meter (Mesa Laborato-

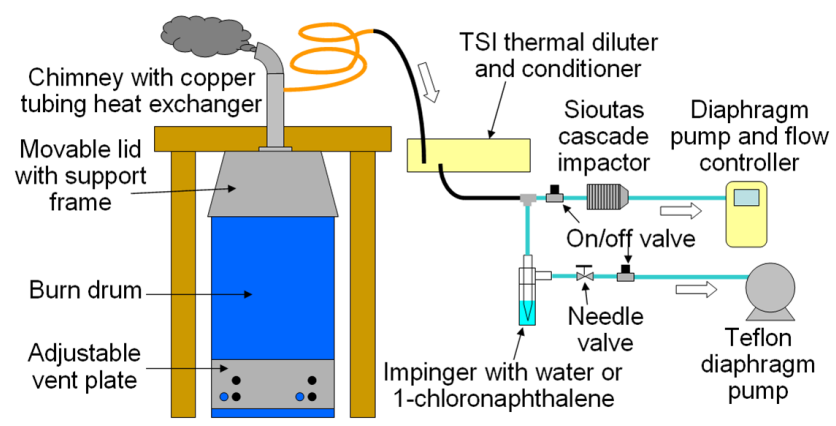

Figure 3. The soot generation setup, consisting of a burning drum, particle conditioning system, SMPS, and impinger and impactor samplers.

ries, model Definer 220) that was factory-calibrated annually and had a listed accuracy of $<1 \%$.

\subsection{Burning facility}

Soot was generated with a burning drum designed in our laboratory (Fig. 3), and burns were conducted at an off-campus location. Burning stages were differentiated visually. This burn drum was equipped with adjustable vents and a lid that was attached to a support structure so that it could fit tightly over the drum or only partially cover it, as needed. Smoke moving through the lid exits a steel chimney pipe, which was sampled by a $0.5 \mathrm{in}$. inner diameter copper tube that acted as a passively cooled heat exchanger. A Teflon tube connected the heat exchanger to a cross, where particles are sampled by a cascade impactor, a liquid impinger (AGI-4; Grinshpun et al., 1997; Lin et al., 1997), and an SMPS. This resulted in a suspension of black carbon in water, though some of it may have dissolved (Miljevic et al., 2012). A sampling time of $\leq 30 \mathrm{~min}$, a volume of collection fluid of $30 \mathrm{~mL}$, and a flow rate of $12.5 \mathrm{~L} \mathrm{~min}^{-1}$ was used (Reponen et al., 2011). The residence time from combustion to sampling was on the order of tens of seconds. All wood samples consisted of heartwood, sapwood, cambium, and bark. They were not green, and were air-dried for at least several months prior to burning. A Sioutas cascade impactor was used with a Leleand Legacy pump to collect the soot on aluminum filters, to allow visual analysis using a scanning electron microscope (SEM). The samples were collected between $30 \mathrm{~s}$ and $3 \mathrm{~min}$, depending on aerosol load. For times much longer than this, the pump on the impactor began to clog and our filters became saturated. The filters were then removed from the impactor and stored in Ziploc bags until later analysis. Filters were analyzed without further processing on a Zeiss EVO SL10 SEM.

The impinger, which contains water, is transferred to glass bottles with Teflon-lined lids and brought to our lab. Samples were diluted and sonicated prior to their introduction to CRDS and the nephelometer, and samples were agitated us- 


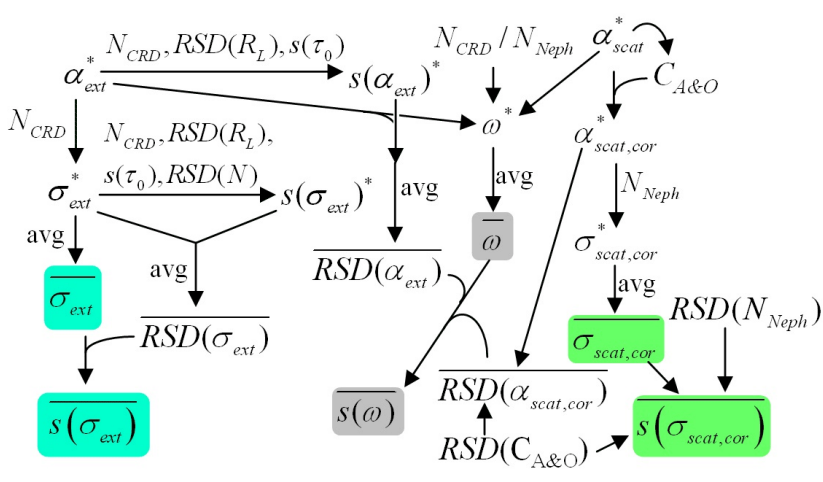

Figure 4. The calculation flow for determining average $\sigma_{\text {ext }}, \sigma_{\text {scat }}$, $\omega$, and their errors. Variables with an asterisk represent individual measurements. $\sigma_{\text {ext }}$ for each experiment is derived from the $\alpha_{\text {ext }}$ and the number density within the cavity, via Eq. (1). This number density is found using Eq. 3. The standard deviation of $\sigma_{\text {ext }}$ for each experiment is found using Eq. (2). The RSD of $\sigma_{\text {ext }}$ for each experiment is found, averaged, and multiplied by the average $\sigma_{\text {ext }}$ to get the average standard deviation of $\sigma_{\text {ext }} . \alpha_{\text {scat }}$ for each experiment is corrected, and $\sigma_{\text {scat }}$ is found using the number density in the nephelometer. This is averaged, and its standard deviation is found from the run-to-run variability of $\sigma_{\text {scat }}$, the RSD of $N_{\mathrm{Neph}}$, and the correction factor error. The RSD of $\alpha_{\text {scat }}$ is based on the run-to-run variability of $\alpha_{\text {scat }}$ and the correction factor error. The SSA of each run is based on $\alpha_{\text {scat }}$ and $\alpha_{\text {ext }}$ for each run and the number-density relationship. This is averaged, and the run-to-run variability of SSA is determined. This variability is used, along with the RSD of $\alpha_{\text {scat }}$ and $\alpha_{\text {ext }}$, to determine the SSA error.

ing a magnetic stir bar throughout atomization. The TSI atomizer had been modified to incorporate a stir plate and accept wide-mouth bottles, which reduce the number of sample transfers and decrease the likelihood of sample carryover. Samples were characterized for their particle size distribution before and after nebulization using an SMPS, and several sizes of soot particles were selected for measuring their optical properties. Baseline measurements were taken with nebulized water without particles to take into account any possible particles generated from residues in the water and to minimize the change in water vapor concentration between the blank and particle measurement experiments. The DMA was set to the same pass diameter as the normal particle measurement, and $\tau_{0}$ was recorded at either 0.2 or $0.5 \mathrm{~nm}$ increments over the wavelength range of the mirror. At each wavelength, $\tau_{0}$ was measured at $20 \mathrm{~Hz}$ for $30 \mathrm{~s}$, producing an average of 600 measurements. Values were averaged over three separate experiments. Blank scattering coefficient measurements were recorded by the nephelometer during this time period and, though they were several orders of magnitude smaller than particle measurements, were subtracted from particle measurements. Particles were then introduced to the system, and readings from the CRDS, nephelometer, and WCPC were allowed to stabilize.
The extinction and scattering cross section of fresh soot from white pine, red oak, and cedar were measured using the CRDS and nephelometer, which were used to calculate the absorption cross section and single scattering albedo. The measurements were made for two wavelength ranges, 500 580 and $580-660 \mathrm{~nm}$. Earlier the measurements were done on different days for each wavelength range, since it involved changing mirrors and conducting realignment of the laser beam, though some later measurements were performed on the same day. Particle number density also varied somewhat over the experiment, but remained mostly consistent. Experiments where the number densities were found to fluctuate significantly were disregarded. The ring-down time was different in each run due to different high-reflectivity (HR) mirrors used for each wavelength range. The error was higher on the low end of the spectrum, due to decreased mirror reflectivity. We have extensively discussed the method used to calculate optical parameters and their associated errors in Singh et al. (2014), and the same method is applied to soot samples in this work.

\section{Results and discussion}

The initial sample collection was done on 3 November 2014. The method of soot collection in distilled water has not been previously reported. We cannot account for any chemical modification of the soot during impingement with our current instrumental capabilities. A comparison of the size distributions of white pine during combustion and after renebulization showed a change in the particle size distribution. The flaming sample had a mode number-density diameter of $148 \mathrm{~nm}$ during the burn (interpolated from peak edges due to detector overload) and $55 \mathrm{~nm}$ upon nebulization. The smoldering stage sample similarly went from a mode diameter of $138 \mathrm{~nm}$ during the burn to $50 \mathrm{~nm}$ after nebulization. In both cases, the mode diameter is reduced by a factor of $\sim 2.7$. However, it is not known whether the optical properties of size-selected particles change due to this sampling process. Once soot was in solution, though, it did not display any change in size distribution over several weeks, which makes it a potentially viable method of sample storage. Chemical analysis would be needed to account for any chemical change, which was not available in this work. Future work will explicitly investigate how well this sampling method conserves the optical properties of size-selected soot. Since some aerosol properties change following impingement and nebulization, the state of soot in this work could be more reflective of fresh soot that has undergone cloud processing in the atmosphere (i.e., deliquescence followed by droplet evaporation). However, many important processes did not take place for these samples, including photochemical transformations. As such, results in this work will only be compared to literature observations of fresh soot. 
Extinction, scattering, and absorption cross sections showed a decrease at higher wavelengths for measurements done several weeks apart (i.e., a different wavelength range at a different time). Even at overlapping wavelengths, older samples had lower cross section values, resulting in an abrupt discontinuity at $580 \mathrm{~nm}$ (the boundary between the ranges of the two sets of mirrors used in this work). Even though the size distribution did not change over the course of several weeks, we attempted to attribute the decrease in optical values to either changes in chemical properties of the soot or to an experimental artifact. When measurements were done on the same day for both wavelength ranges, the abrupt change in the measured values was reduced for most runs, showing this discontinuity. The discontinuity could be a result of several factors, including extinction coefficient error, which is about $1.3-1.7 \%(1 \mathrm{~s})$, and the run-to-run variability is similar $(\sim 2 \%)$; there is variation in the particle concentration between runs, the cross section error being just over $10 \%$, and actual changes in the sample. To adjust measurements performed on different days, a constant was derived from the difference in cross section values at $580 \mathrm{~nm}$ for each wavelength range. While values from 500 to $580 \mathrm{~nm}$ were kept the same, this constant was added or subtracted to the extinction and scattering cross section values $580-660 \mathrm{~nm}$. The higher wavelength range was adjusted because it had poorer $S / N$ due to lower mirror reflectivity. In all cases, the SSA did not change significantly due to adjusting the extinction and scattering values. Measurements were done several times on different days, and the results are consistent. In general, the cross sections of soot particles decreased with increasing wavelength.

Figure 4 shows the steps followed in determining cross sections, SSA, and their errors. For extinction, the coefficient is measured at a particular size and wavelength multiple times (individually denoted by *). The error (1 standard deviation, SD) is derived from this. The relative standard deviation (RSD) of several factors is used to calculate the average cross section and average error from the original extinction coefficient. A similar process is shown for scattering with the inclusion of a correction factor and its associated error. A broadband correction factor $A_{\mathrm{Neph}}$ is used to reconcile scattering with extinction for completely scattering particles (Singh et al., 2014). The empirical Ångstrom-exponentbased correction of Anderson and Ogren (1998) was used to account for truncation angle error. The SSA and its error are based on scattering and extinction coefficients, the RSD of those coefficients, and the relative number density in the CRDS and nephelometer. The error for each quantity is calculated using Eq. (2) in Singh et al. (2014). The error of extinction coefficient is calculated from Eq. (2).

$$
\begin{aligned}
& \operatorname{SD}\left(\sigma_{\mathrm{ext}}\right)= \\
& \sigma_{\mathrm{ext}} \sqrt{\left(\frac{\mathrm{SD}\left(N_{\mathrm{CPC})}\right.}{N_{\mathrm{CPC}}}\right)^{2}+\frac{1}{N_{\mathrm{RSD}} \mathrm{Vrt}_{s}}+\left(\frac{\mathrm{SD}\left(R_{\mathrm{L}}\right)}{R_{\mathrm{L}}}\right)^{2}+\frac{\mathrm{SD}\left(\tau_{o}\right)^{2}}{\left(\tau-\tau_{o}\right)^{2}}\left(\frac{\tau_{o}^{2}}{\tau^{2}}+\frac{\tau^{2}}{\tau_{o}^{2}}\right)},
\end{aligned}
$$

where $\operatorname{SD}\left(\sigma_{\text {ext }}\right)$ is the standard deviation in the extinction coefficient, $N_{\mathrm{CPC}}$ and $\mathrm{SD}\left(N_{\mathrm{CPC}}\right)$ are the number density in measured by the CPC and its error, respectively, $N_{\mathrm{RSD}}$ is the number density in the ring-down cavity, $R_{\mathrm{L}}$ is the distance occupied by the sample relative to the mirror-to-mirror distance, $\operatorname{SD}\left(R_{\mathrm{L}}\right)$ is the error associated with measurement of $R_{\mathrm{L}}, t_{\mathrm{S}}$ is the averaging time ( $\left.30 \mathrm{~s}\right), r$ is the sampling repetition rate $(20 \mathrm{~Hz})$, and $V$ is the beam volume. $\operatorname{SD}\left(\tau_{o}\right)$ is the standard deviation of the blank ring-down time.

The particle number density in the cavity $\left(N_{\mathrm{CRD}}\right)$ is assumed to be, on average, between the particle concentration entering and exiting the CRDS. By measuring the particle loss in nephelometer $\left(L_{\mathrm{Neph}}\right)$ and cavity $\left(L_{\mathrm{CRD}}\right)$ for each particle size, the number density in the nephelometer $\left(N_{\mathrm{Neph}}\right)$ and cavity is calculated from the CPC measurement $\left(N_{\mathrm{CPC}}\right)$ using the following equation:

$N_{\mathrm{Neph}}=\frac{N_{\mathrm{CPC}}}{L_{\mathrm{Neph}}}$ and $N_{\mathrm{CRD}}=\frac{N_{\mathrm{CPC}}}{2 L_{\mathrm{Neph}}}\left(\frac{1}{L_{\mathrm{CRD}}}+1\right)$.

The accuracy of SSA, based on extinction and scattering, is limited largely by the nephelometer at low SSA values. Specifically, the truncation angle correction $C(\lambda)$ is the limiting factor, which is discussed by Bond et al. (2009). Changes in the particle size alter the degree of angular scattering, which in turn changes $C(\lambda) . C(\lambda)$ is expected to have a $\leq 1 \%$ error for SSA values greater than $0.9,<2 \%$ for values $0.8-$ 0.9 , and $\sim 5 \%$ for values lower than 0.7. Bond et al. suggest that if Anderson \& Ogren-corrected SSA is larger than 0.9 , then using $C(\lambda)$ is acceptable. Under other conditions where the error is considered unacceptable, especially those found in laboratory or field measurements of biomass or biofuel combustion, the $C(\lambda)$ systematic error can be as high as $5 \%$. To reduce the scattering error for low SSA particles, it is suggested that the size distribution should be measured, and a refractive index should be assumed. Assuming a refractive index does not cause systematic errors above $2 \%$, but this method is definitely difficult, and size distribution errors must be constrained to avoid error commensurate with using the Anderson \& Ogren method. Assuming this error can be maintained $\leq 2 \%$, a mean SSA error of $\leq 2.9 \%$ is expected using this method (Singh et al., 2014). Using the method of Bond et al. (2009), scattering error was estimated using the observed SSA and Ångstrom absorption exponent (AAE), and was found to be 3-6\%. The uncertainty for using CRDS and nephelometry with this technique to measure SSA of fresh soot is estimated to be less than 2-6\%.

As BB particles age, aerosol growth is not the only means in which they change. Often, dilutors are used in laboratory 
Table 1. Mean SSA values, their error $(1 \sigma)$, and AAE in the 500$580 \mathrm{~nm}$ wavelength range.

\begin{tabular}{lrr|cc}
\hline \multirow{2}{*}{ Particle } & \multicolumn{2}{c|}{ SSA } & \multicolumn{2}{c}{ AAE } \\
\cline { 2 - 5 } Size, fuel & Flaming & Smoldering & Flaming & Smoldering \\
\hline 300 nm, cedar & $0.55 \pm 0.03$ & $0.46 \pm 0.03$ & 3.34 & 4.53 \\
300 nm, red oak & $0.56 \pm 0.03$ & $0.54 \pm 0.02$ & 2.13 & 3.04 \\
300 nm, white pine & $0.55 \pm 0.05$ & $0.50 \pm 0.03$ & 3.12 & 3.92 \\
400 nm, cedar & $0.58 \pm 0.05$ & $0.61 \pm 0.05$ & 2.08 & 2.39 \\
400 nm, red oak & $0.53 \pm 0.04$ & $0.60 \pm 0.03$ & 3.51 & 3.90 \\
400 nm, white pine & $0.46 \pm 0.03$ & $0.56 \pm 0.05$ & 3.09 & 4.20 \\
500 nm, cedar & $0.50 \pm 0.05$ & $0.64 \pm 0.06$ & 1.59 & 2.75 \\
500 nm, red oak & $0.63 \pm 0.06$ & $0.68 \pm 0.06$ & 3.58 & 5.57 \\
500 nm, white pine & $0.71 \pm 0.04$ & $0.74 \pm 0.06$ & 2.17 & 3.24 \\
\hline
\end{tabular}

and field experiments on $\mathrm{BB}$ emissions to represent dilution due to diffusion in the atmosphere. These coatings can evaporate substantially during dilution of a smoke plume to ambient conditions. While the generation of volatile compounds cannot be ruled out in our work, we did not take into account the impact this may have on the optical properties of the soot samples collected in this work. In the sampling system used in this work, any coating on the soot could be lost (i.e., dissolved) after being impinged, and would make the measurement of the resuspended soot core drastically different from a core shell or more complex coating structure that might be generated. Alternatively, previously uncoated particles could be coated with water-soluble, but nonvolatile or semivolatile species. We aim to systematically address these issues in future work, when these measurements become available.

It has been shown that the presence of large, multiply charged particles passed by the DMA can artificially increase measured cross sections, even if their number density is relatively small (Uin et al., 2011). An inline impactor with a $1 \mu \mathrm{m}$ cutoff diameter or larger has been successfully used to exclude multiply charged particles from a gas stream (Mellon et al., 2011). Of course, this method is limited to particle diameters of $500 \mathrm{~nm}$ or larger. For smaller particle diameters, a separate experiment must be performed. NIST scientists have used an aerosol particle mass analyzer to take an aerosol stream that has been size-selected with a DMA and separate it by mass. Consequently particles that have the same electrical mobility, but different mobility diameters were separated. This method had its own limitations for irregularly shaped particles (in this case, it includes soot; Radney et al., 2013). Unfortunately, our lab is not equipped with this instrument, and possible errors due to multiply charged species have been ignored. Previous work in our laboratory on polystyrene spheres revealed that multiple charging and surfactant coating could significantly increase extinction and scattering measurements when these were compared to Mie theory (Singh et al., 2014). It was found that the technique used in this work, and similar instruments, was limited to particles with diameters $\geq 200 \mathrm{~nm}$, which was a restriction followed in this work.

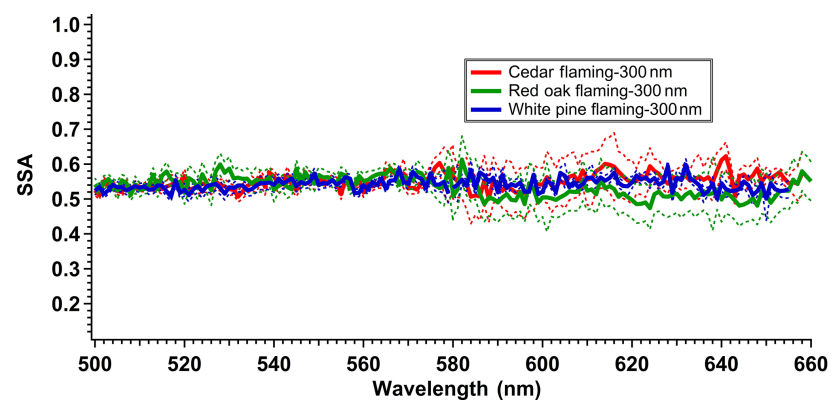

Figure 5. SSA of $300 \mathrm{~nm}$ particles from white pine, red oak, and cedar sampled during the flaming stage.

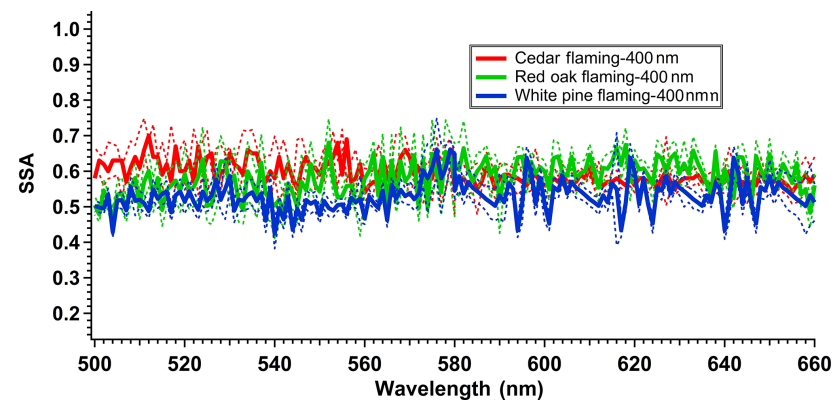

Figure 6. SSA of $400 \mathrm{~nm}$ particles from white pine, red oak, and cedar sampled during the flaming stage.

The SSA as a function of wavelength for fresh soot produced from cedar, red oak, and white pine had a slope close to zero over the wavelength range of 500-660 nm, with values ranging from 0.46 to 0.74 . While our measured optical properties of fresh soot are within the range of values measured by other groups, reflecting both the dynamic nature of fires, these variations may be due to significant differences in smoke aging processes, burning conditions, sample handling and processing, and measurement techniques used (Schnaiter et al., 2005a; Lewis et al., 2008; Mack et al., 2010; Liu et al., 2014). The SSA for cedar, red oak, and white pine were plotted for 300,400 , and $500 \mathrm{~nm}$ particles during the flaming stage (Figs. 5, 6 and 7) and during the smoldering stage (Figs. 8, 9 and 10). The solid lines represent the mean values of SSA, and the dotted lines represent error about the mean. The mean values and their errors are shown in Table 1. Cedar had an SSA that was significantly greater for the flaming stage than the smoldering stage for $300 \mathrm{~nm}$ particles. The smoldering stage was greater than flaming for larger particles, but not significantly for $400 \mathrm{~nm}$ particles. It has been shown that the smoldering phase emits larger, higher SSA particles (Reid et al., 2005). It is likely that, at small particle diameters, such as $300 \mathrm{~nm}$, elemental carbon (EC) has a greater contribution to particle mass than OC, giving rise to lower SSA values for the smoldering stage of this fuel at this size. To make up for this, larger particles could have a greater contribution of $\mathrm{OC}$, resulting in its greater abundance in par- 
ticulate matter with a diameter of less than $2.5 \mu \mathrm{m}\left(\mathrm{PM}_{2.5}\right)$. This is consistent with the larger observed SSA values for larger diameter particles in the smoldering stage of cedar combustion. Red oak had SSA values that were comparable for $300 \mathrm{~nm}$ particles, greater for smoldering for $400 \mathrm{~nm}$ particles, and slightly greater for smoldering $500 \mathrm{~nm}$ particles. White pine behaved similarly, though the flaming stage had a slightly greater SSA for $300 \mathrm{~nm}$ particles. The smoldering combustion phase has been observed to emit larger particles with a higher scattering efficiency (Chen et al., 2006). Smoldering fires often lead to $\mathrm{BrC}$, which is less absorbing than BC (Chakrabarty et al., 2010). While this may explain some of these observations, it is clearly not a rule, given contradictory values for $300 \mathrm{~nm}$ particles. Additionally, for larger particles where the mean SSA for smoldering particles was greater than flaming particles, half of them did not have a statistically significant difference.

The SSA values of fresh soot from the smoldering stage for 300,400 , and $500 \mathrm{~nm}$ particle sizes, are slightly dependent on size parameter $(\chi)$ and range from 0.46 to 0.71 , as shown in Fig. 11. The SSA of these fuels vs. $\chi$ was plotted in Fig. 12 for the flaming stage, and had values $0.50-0.71$. Size-segregated measurements of SSA seem to be more variable for the smoldering stage than the flaming stage, though this conclusion is based on a limited set of data. For each fuel investigated, the SSA values of the smoldering stage became slightly larger as particle size increased (i.e., they become more scattering). Reid et al. have suggested that smoldering combustion may produce larger particles than flaming combustion due to a greater contribution of a nonabsorbing component containing OC (Reid et al., 2005). This is consistent with the result of others, where flaming-dominated fires had higher mass fractions of $\mathrm{BC}$, while smoldering fires produced roughly 4 times as much $\mathrm{OC}$ as flaming-dominated fires (McMeeking, 2008). This is also consistent with Tumolva et al. (2010), who observed that the flaming stage of white oak produced significant quantities of fractal-like particles, while smoldering pine bark predominantly produced tar-ball-like spheres. For the flaming stage, there was no observable trend as a function of particle size. All species tended to have equivalent SSA values for $300 \mathrm{~nm}$ particles, but diverged significantly at larger diameters. While wavelength does not seem to significantly affect SSA in this work, the particle size clearly plays a major role in determining the scattering or absorption properties of the particle.

A number of ambient field studies on optical properties of BB aerosols have been done, several of which are reported in Table 2. These were mainly measured at a single wavelength, but not all were done at the same wavelength. In general, soot particles generated by burning propane or ethylene in the laboratory or emitted from diesel engines have a much lower SSA than BB soot (Wei et al., 2013; Khalizov et al., 2009a; Schnaiter et al., 2005a; Schnaiter et al., 2006; Radney et al., 2014). Liu et al. (2014) measured SSA and AAE of fresh BB aerosols produced from 92 controlled laboratory

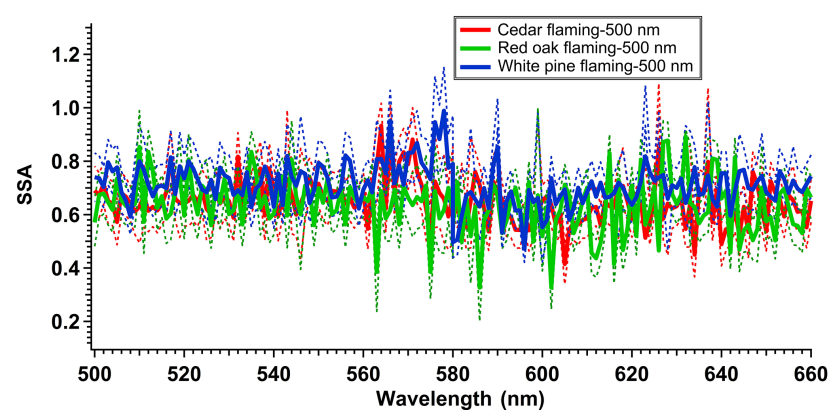

Figure 7. SSA of $500 \mathrm{~nm}$ particles from white pine, red oak, and cedar sampled during the flaming stage.

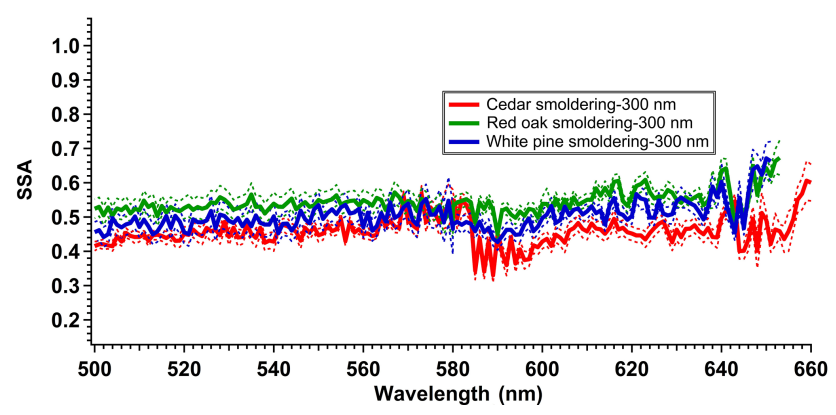

Figure 8. SSA of $300 \mathrm{~nm}$ particles from white pine, red oak, and cedar sampled during the smoldering stage.

combustion experiments of 20 different woods (ponderosa pine (PP), red oak, wheat straw, rice straw, and others) and a relatively fresh plume during a field-based measurement of the Las Conchas wildfire in 2011. They demonstrated that an SSA of BB aerosol spans a large range $(\sim 0.2-1)$, and SSA varies strongly with fire-integrated modified combustion efficiency $\left(\mathrm{MCE}_{\mathrm{FI}}\right)$, which is a measure of how cleanly a fuel is combusted. They found that SSA is close to 1 between 532 and $781 \mathrm{~nm}$, as long as $\mathrm{MCE}_{\mathrm{FI}}$ is below $\sim 0.85$. At higher $\mathrm{MCE}_{\mathrm{FI}}$ values, SSA drops precipitously and exhibits greater spectral dependence, which corresponds to a lower OC content. This study also showed that both SSA and AAE increase with aging. We find that our SSA values for red oak (0.53-0.68) are fairly close to the observations of Liu et al. $(0.45-0.59$ at $532 \mathrm{~nm})$. It is possible that the slightly smaller value observed by Liu et al. is due to the use of a cooking stove, which combusts more cleanly than an open burn. Our flaming and smoldering SSA values for white pine (0.46-0.74) were significantly different than PP, either a mix of brown and green $(0.97$ at $532 \mathrm{~nm})$ or all green $(0.93-0.99$ at $532 \mathrm{~nm}$ ). This was an open burn, performed similarly to our work, which shows that, even within types of pine, drastic differences in SSA (0.19-0.53) can be observed between species.

Bergstrom et al. (2003) performed broadband SSA estimates of the total aerosol column using solar radiative flux and optical depth measurements over 2 days during the SA- 
Table 2. Previous SSA measurements of fresh BB aerosols.

\begin{tabular}{|c|c|c|c|c|}
\hline Reference & Wavelength (nm) & Sample & SSA range & Method \\
\hline Schnaiter et al. (2005b) & 550 & Corn stems & 0.74 & $\begin{array}{l}\text { Long-path extinction } \\
\text { spectrometer and nephelometer }\end{array}$ \\
\hline Lewis et al. (2008) & 405 and 870 & $\begin{array}{l}\text { Laboratory smoke from } \\
\text { a variety of biomass fuels, } \\
\text { including pine and rice straw }\end{array}$ & $0.37-0.95$ & $\begin{array}{l}\text { Dual-wavelength } \\
\text { photoacoustic instrument } \\
\text { and nephelometer }\end{array}$ \\
\hline Mack et al. (2010) & 532 & $\begin{array}{l}\text { Laboratory measurements of } \\
\text { fresh smoke from wild land } \\
\text { fuels in the W and SE USA }\end{array}$ & $0.428-0.99$ & $\begin{array}{l}\text { Photoacoustic and } \\
\text { nephelometer }\end{array}$ \\
\hline Liu et. al. (2014) & $\begin{array}{l}405,532, \\
\text { and } 781\end{array}$ & $\begin{array}{l}\text { Fresh BB aerosols from } \\
\text { the controlled laboratory } \\
\text { combustion of } 20 \text { woods and grasses }\end{array}$ & $0.2-1.0$ & $\begin{array}{l}\text { Three-wavelength } \\
\text { photoacoustic soot } \\
\text { spectrometer and nephelometer }\end{array}$ \\
\hline
\end{tabular}

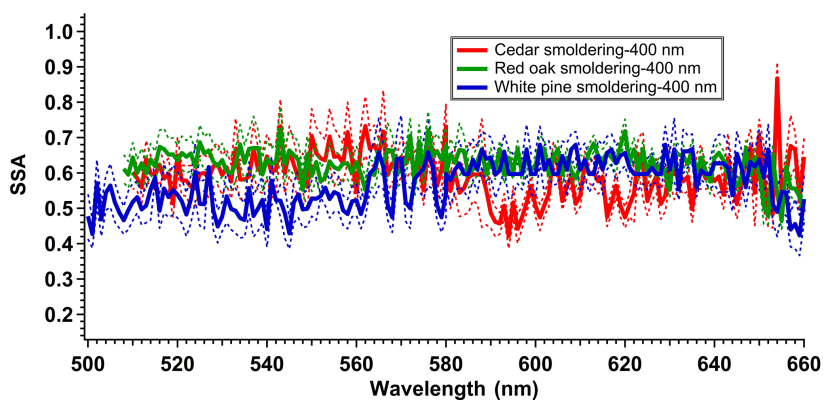

Figure 9. SSA of $400 \mathrm{~nm}$ particles from white pine, red oak, and cedar sampled during the smoldering stage.

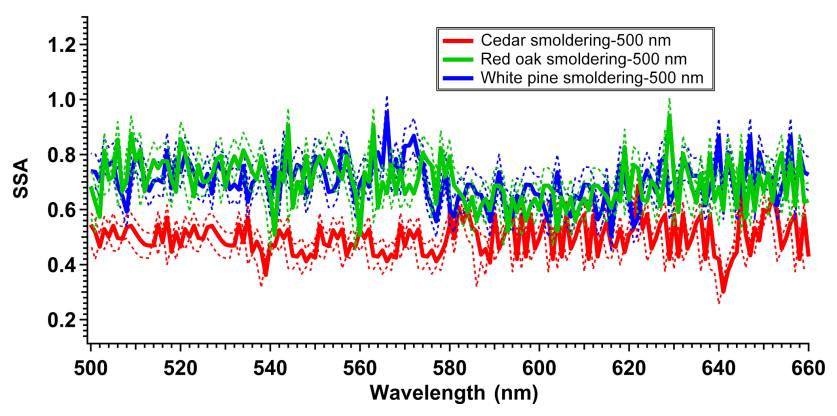

Figure 10. SSA of $500 \mathrm{~nm}$ particles from white pine, red oak, and cedar sampled during the smoldering stage.

FARI 2000 field experiment in southern Africa. A detailed radiative transfer model resulted in SSA values from 0.85 to 0.90 at $350 \mathrm{~nm}$, decreasing to 0.6 in the near-infrared (Bergstrom et al., 2003). Observations with small optical depth over the ocean showed a slightly decreasing SSA with wavelength, $0.84 \pm 0.06$ at 500 and $0.79 \pm 0.11$ at $660 \mathrm{~nm}$. When sampling springtime BB haze over Mongu, Zambia, however, a very high optical depth was observed and SSA had little spectral dependence in this region $(0.87 \pm 0.01$ at 500 and $0.86 \pm 0.02$ at $660 \mathrm{~nm}$ ). While this SSA is higher than our measurements, the same lack of spectral dependence is observed. In aircraft measurements by Johnson et al. (2008), the SSA of BB aerosols over western Africa during the Dust and Biomass Experiment (DABEX) varied from 0.73 to 0.93 at $550 \mathrm{~nm}$. After removing a contribution for mineral dust, they found an SSA around $0.81 \pm 0.08$ for both aged and fresh smoke plumes from agricultural fires. This SSA value is higher than our observations for fresh soot by approximately $0.05-0.35$, which could be due to the presence of silica from the agricultural refuse of many silica-rich crops (millet, maize, sorghum, and other grains). A similar explanation can be given for differences between our results and the SAFARI campaign estimates, though no source attribution was performed in this case, and mineral dust could have contributed to those measurements. Alados-Arboledas et al. (2011) monitored a fresh BB plume using a combination of Raman lidar and star- and sun-photometers, finding relatively low SSA values of $0.76-0.86$, with lower values for fresh BB aerosols than aged smoke. Three-wavelength measurements by Liu et al. (2014) shows fire-integrated, fitted SSA values at $405 \mathrm{~nm}$ to be slightly smaller than those at $532 \mathrm{~nm}$ by $4-5 \%$, where the difference becomes larger for increasing $\mathrm{MCE}_{\mathrm{FI}}$, but only slightly. SSA values at 532 and $781 \mathrm{~nm}$ are nearly equivalent (5\% difference) over a wide range of $\mathrm{MCE}_{\mathrm{FI}}$, but begin to diverge drastically when $\mathrm{MCE}_{\mathrm{FI}}>0.92$, with the SSA at $532 \mathrm{~nm}$ being the larger value. This observation bounds the $\mathrm{MCE}_{\mathrm{FI}}$ of burns performed in this work to $<0.92$. While field measurements and remote sensing retrievals of SSA rarely fall below 0.6 in ambient plumes, the differences in SSA among BB aerosols are attributed to changes in combustion conditions produced by different fuel types as well as soot age (Eck et al., 2003; Lewis et al., 2008; Mack et al., 2010). In comparison to these field observations, our results are lower than is typically seen for fresh soot, even when external mixing is taken into account. This could suggest that the MCE values of wildfires are lower than controlled laboratory burns, likely due to the lower abundance of oxygen in wildfires. However, our lowest observed SSA was during a smoldering burn of cedar $(0.46$ average), which should have a relatively low MCE. The difference in SSA due to fuel type is at least 0.15 and could 
be much greater $(\sim 0.4)$, when comparing this work to field observations of fresh soot. Clearly, fuel type or some other factor, such as the presence of very scattering particles that are larger than those studied here, plays an important role.

Lewis et al. (2008) found SSA values at $405 \mathrm{~nm}$ ranging from 0.37 to 0.95 for flowering shrubs and pine needle litter during the Fire Laboratory at Missoula Experiment (FLAME). Chemical and physical properties determined from X-ray and electron microscopy methods found that the combustion products of pine needles, wood, and litter (duff) are chemically similar, and their particles consist of liquid oily OC with BC inclusions (Hopkins et al., 2007). PP needles/twigs and duff were found to have a fireintegrated SSA of 0.91 and 0.97 , respectively, which is significantly larger than any of our white pine measurements (Table 1), despite having similar burning conditions. BB aerosols of southern longleaf pine needles were also significantly greater, having an SSA of 0.89 . While some of this variability can be attributed to $\mathrm{sp}^{2}$ hybridization, which should be related to MCE, SSA values observed in this work were different than wood species investigated by Hopkins et al. SSA values observed in this work were commensurate with shrubs in Hopkins et al., where particles were mainly $\mathrm{BC}$ with inorganic inclusions. Given the presence of tar balls in this work, the variability in the SSA of $\mathrm{BrC}$-coated $\mathrm{BC}$ is clearly greater than previous measurements. In preliminary data presented in a meeting following NASA measurements during SEAC4RS, involving in situ sampling of the smoke from the Yosemite Rim Fire, the initial SSA of smoke was 0.92 , increased in the first $0-7 \mathrm{~h}$ to 0.96 , and was nearly constant after that (up to 2 days; Beyersdorf, 2013). This is significantly higher than our SSA values for fuels studied in this work. This area of Yosemite was in the lower montane forest zone, which predominantly had California black oak, PP, incense cedar, and white fir. Fresh smoke in the Rim Fire is commensurate in SSA to BB particles from PP needles and twigs (SSA of 0.91 at $532 \mathrm{~nm}$ ) (Hopkins et al., 2007). However, this was lower than either PP duff or a mix of brown and green PP wood, which have an SSA of 0.97 at $532 \mathrm{~nm}$ (Hopkins et al., 2007; Liu et al., 2014). This could be due to the presence of significant quantities of very old fuel on the ground, which could produce more efficient combustion. Chen et al. (2006) reported SSA values of $0.35-0.70$ for dried PP wood in controlled laboratory combustion studies, which supports this assertion. Chen et al. (2006) also observed an SSA of 0.70 for white pine needles during the smoldering stage in controlled laboratory combustion studies, which is in fair agreement with white pine soot in our work (0.460.74). Another in situ observation of SSA aging was done on a BB plume in the Yukatan peninsula (Yokelson et al., 2009; Pokhrel et al., 2016). The SSA at a wavelength of $520 \mathrm{~nm}$ was observed to change from $\sim 0.75$ to $\sim 0.93$ over $1.4 \mathrm{~h}$ of aging.

AAE values determined in this work are presented in Table 1 . By making a $\log _{10}-\log _{10}$ plot of the absorption cross

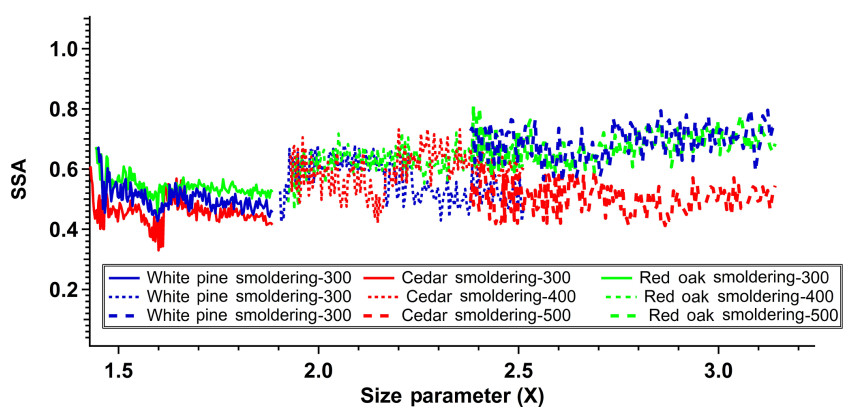

Figure 11. SSA as a function of size parameter for all samples in the smoldering stage.

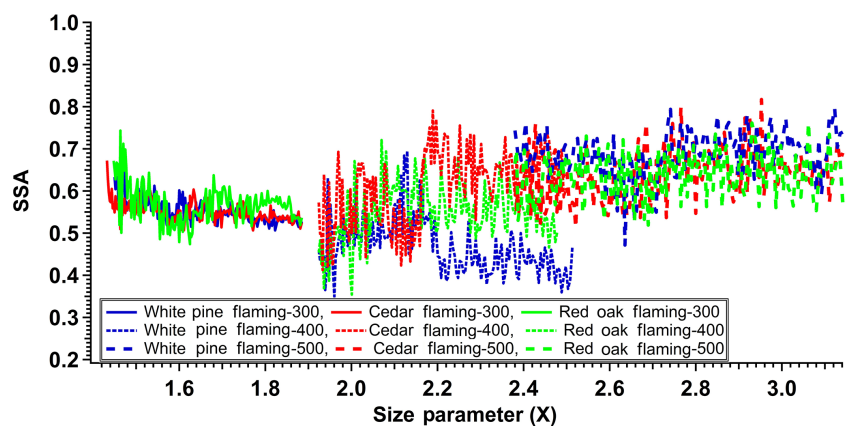

Figure 12. SSA as a function of size parameter for all samples in the flaming stage.

section $\left(\sigma_{\mathrm{abs}}\right)$ vs. $\lambda$, a linear fit was performed to yield the AAE. Significant errors were observed in the range of 580$660 \mathrm{~nm}$ due to the mirrors being less reflective. As such, fits were only performed from $500-580 \mathrm{~nm}$. Saleh et al. (2013) measured AAE for a variety of fuels, and found values of 1.38 for fresh oak, 1.42 for aged oak, 1.48 for fresh pocosin pine, 1.73 for aged pocosin pine, and 2.15 for fresh gallberry. These values are consistent with other measurements for BB emissions (Liu et al., 2014; Saleh et al., 2013; Gyawali et al., 2009; Habib et al., 2008). Liu et al. (2014) observed AAE values for red oak (1.16-1.24) that were lower than our observations for either burning stage (2.13-3.58 for flaming and 3.04-5.57 for smoldering). This difference could be due to the burner, where a cleaner burning flame leads to higher MCE, lower SSA, and lower AAE as the fraction of BC increases. In contrast to SSA, AAE values for white pine in this work $(2.17-4.20)$ are similar to values of Liu et al. for PP (2.9 for mixed brown/green and 1.99-4.60 for green). While they do observe a regime where there are such large values, and large variability in those values, they observe this for SSA values $>0.8$ at $405 \mathrm{~nm}$ or $>0.85$ at $532 \mathrm{~nm}$. This is inconsistent with the relatively low SSA values for white pine observed in this work. Cedar is also incongruent with the observations of Liu et al., since relatively large AAE values were observed for the flaming stage (0.70-3.3), but small SSA values $(0.50-0.61)$ were observed. The incon- 


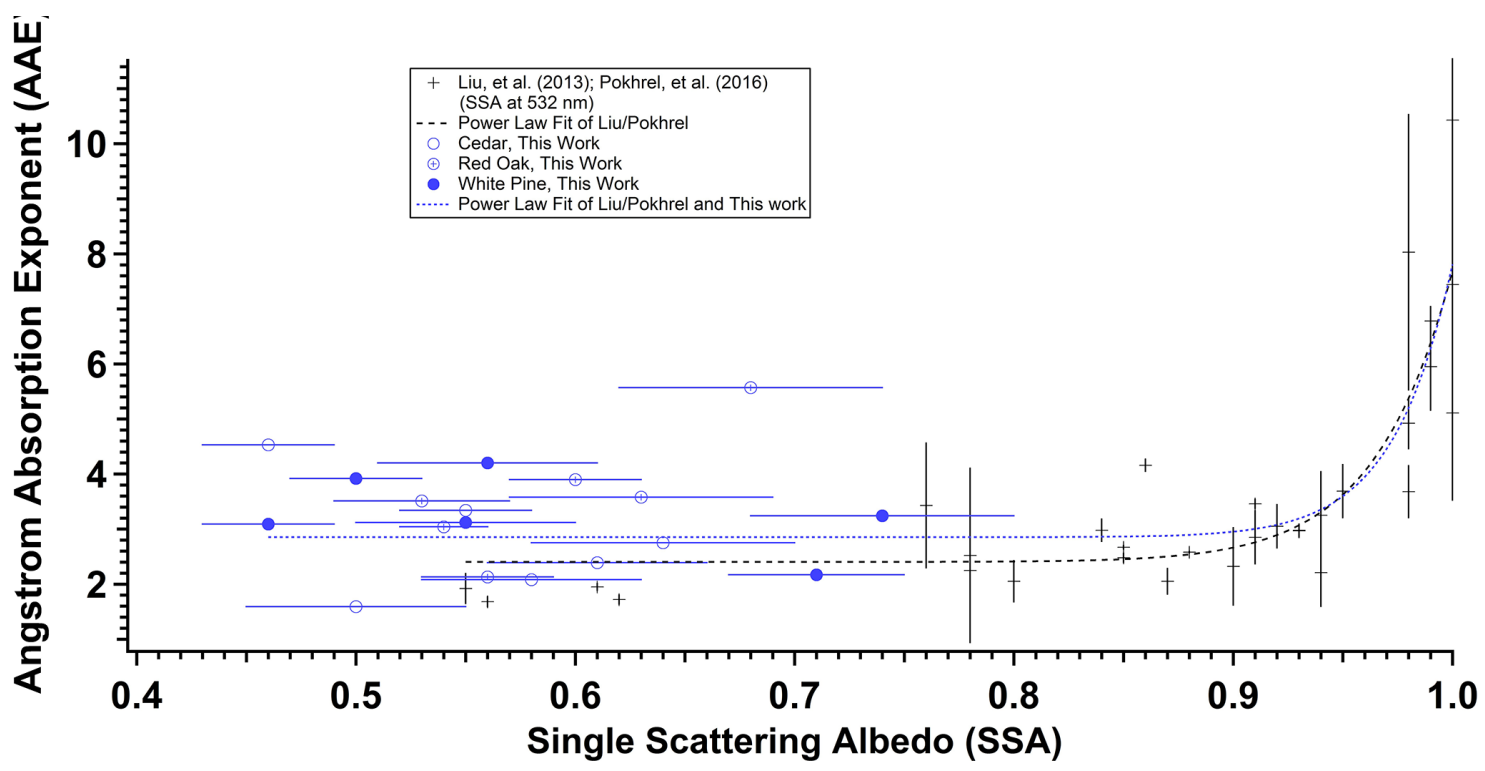

Figure 13. Results of this work compared to FLAME-4 results (Liu et al, 2013; Pokhrel et al., 2016). A power law fit was performed in the form of $\mathrm{AAE}=a+b \mathrm{SSA}^{c}$ was performed for FLAME-4 and combined data. For FLAME-5, $a=2.402 \pm 0.296, b=5.298 \pm 0.587$, and $c=28.53 \pm 8.42$. For the combined data set, $a=2.852 \pm 0.187, b=4.961 \pm 0.599$, and $c=36.965 \pm 11.300$.

gruence is even more pronounced for the smoldering stage, where AAE is even higher (1.3-4.7), while SSA is about the same, but more variable (0.45-0.64). Lastly, a lack of wavelength dependence in SSA was only observed when MCE was $<0.92$, where SSA values were not observed below 0.8 . This suggests a potential issue with the framework developed by Liu et al. Recently, Pokhrel et al. (2016) found that AAE and SSA had a better dependence on $\mathrm{EC} /(\mathrm{EC}+\mathrm{OC})$ for FLAME-4 measurements. However, we observed AAE values from 2.17 to 4.20 for white pine, which would correspond to an $\mathrm{EC} /(\mathrm{EC}+\mathrm{OC})$ value less than 0.2 , as shown in Fig. 4 of Pokhrel et al. However, Pokhrel et al. show SSA values greater than $\sim 0.75$ at $532 \mathrm{~nm}$ when $\mathrm{EC} /(\mathrm{EC}+\mathrm{OC})$ is less than 0.2. Our observed SSA values range from 0.46 to 0.74 , which is only seen at $\mathrm{EC} /(\mathrm{EC}+\mathrm{OC})$ significantly greater than 0.2. The flaming stage of cedar does not seem to be as problematic in the $\mathrm{EC} /(\mathrm{EC}+\mathrm{OC})$-based scheme. While Liu et al. and Pokhrel et al. plot SSA and AAE against $\mathrm{MCE}, \mathrm{EC} / \mathrm{OC}$, and $\mathrm{EC} /(\mathrm{EC}+\mathrm{OC})$, neither publication plots SSA against AAE. We have done so in Fig. 13, where it can be seen that many of our measurements inhabit a distinct location in AAE/SSA space. The AAE is higher and the SSA is lower than most FLAME-4 observations. Part of this difference may be that previous measurements were done for the entire burn and all diameters below $2.5 \mu \mathrm{m}$, whereas measurements in this work were segregated by size and burning stage. When both data sets were combined and fit to a power law function, the y-offset increased, and the fit had greater power dependence.

For each fuel and particle size, a larger AAE was found for smoldering combustion, compared to the flaming com- bustion stage, which is consistent with a significant absorption by $\mathrm{BrC}$ in the visible region (Chen et al., 2006; Chang and Thompson, 2010). AAE values in this work are generally larger than those observed in relatively fresh plumes from the Las Conchas wildfire $(2.1 \pm 0.5$ at $1 \sigma)$. This may be due to differences in burning conditions or fuel type, where the majority of burning was in the southern Rocky Mountain mesic and dry-mesic montane mixed conifer ecosystems and ponderosa pine woodland (Bird and Menke, 2011). These areas are dominated by Douglas fir, white fir, and ponderosa pine, though blue and mountain spruce are frequently present along with a number of shrub types.

The optical properties of aerosols are dominated by their chemical composition and physical characteristics, such as size and morphology, which lead to large uncertainties in quantifying how they directly alter the climate system. Despite the care taken in measuring SSA and AAE in this work, several of these effects require additional measurements to fully characterize their effects on aerosol optical properties. Freshly emitted BC particles are mostly hydrophobic and externally mixed with other aerosol constituents (Zhang et al., 2008). There is evidence that fires produce BC particles coated with organic matter in a manner that enhances some of their optical properties, specifically short-wavelength absorption by "lensing" (Lack et al., 2012), which alters the results of climate models (Bond and Bergstrom, 2006). We have observed the same tar-ball-like particles in SEM images, but we did not perform further analysis (Tumolva et al., 2010). Field measurements indicate that, during transport, fresh soot becomes internally mixed with sulfates and organics, leading to an enhancement of light absorption by 
about $30 \%$ (Schwarz et al., 2008). Backman et al. (2010) measured the effect of heating on light scattering and absorption by aerosols at an urban background station in Helsinki. Heating mixed aerosols would volatilize scattering and low molecular weight organic constituents, producing an increase in light absorption, with SSA reduced to 0.4 after thermodenuding (Backman et al., 2010). Many of the SSA observations in this work, particularly at 300 and $400 \mathrm{~nm}$ diameters, are within this range. The aging process can also affect the morphology of soot by collapsing dendritic structures into more compact or near-spherical morphologies. Particles' ability to act as cloud condensation nuclei (CCN) is largely controlled by aerosol size rather than composition (Dusek et al., 2006). Field measurements suggest that in mixed aerosol populations, particle size is a good predictor of $\mathrm{CCN}$ ability. Aerosols particles can take up water, become larger in size than their dry equivalents, and hence, scatter more light. Wet particles also have different angular scattering properties and refractive indices than their dry counterparts, even at $50 \%$ relative humidity $(\mathrm{RH})$. An internal mixture of soot with other aerosol components is significantly more absorptive than the external mixture (Jacobson, 2000). The optical properties of fresh (uncoated) soot are practically independent of RH, whereas soot internally mixed with sulfuric acid exhibits significant enhancement in light absorption and scattering, increasing with the mass fraction of sulfuric acid coating and RH (Khalizov et al., 2009b). While these factors are recognized as important in affecting the optical properties of particles, they are not currently well constrained in this work.

One issue that can be addressed is the influence of large, multiply charged particles (with the same electrical mobility as smaller, +1 charged particles) on the optical properties of size-selected aerosols, that is, particles that are double the geometric cross section and have a +2 charge, 3 times these factors, etc. A particle with double the geometric cross section for 300,400 , and $500 \mathrm{~nm}$ particles would have diameters of 424,566 , and $707 \mathrm{~nm}$. Since the latter two are much larger than those studied here, we will limit our discussion to 300 and $424 \mathrm{~nm}$ particles (the latter is assumed to have the same optical properties as $400 \mathrm{~nm}$ particles). For the smoldering stage of cedar combustion, which exhibits the greatest difference in SSA between 300 and $400 \mathrm{~nm}$ particles, the proportion of $300: 424 \mathrm{~nm}$ particles was $\sim 4.2: 1$ according to their SMPS particle number density, which corrects for multiple charging. Using the equations of Wiedensohler (1988) with corrected values, we determined that the mobility-selected particles consisted of $>89 \%$ of +1 charged, $300 \mathrm{~nm}$ particles and $<11 \%$ of +2 charged, $424 \mathrm{~nm}$ particles. This would decrease the observed SSA of smoldering cedar by 0.018 (3.9\%), which can, in some cases, be significant (Bond et al., 2009). This is the largest difference observed, however. A similar treatment was done to red oak combustion, which showed an increase in SSA of $0.0026(0.47 \%)$ and a decrease of $0.0064(1.2 \%)$ for the flaming and smoldering stages, respectively. Neither of these is significant.

\section{Conclusions}

Though there were differences in the size distribution between sampling and nebulization, and chemical analysis was not available for this work, samples appeared to be stable over the course of 2-4 weeks. A systematic study is planned to determine the suitability of this sampling technique for storing soot samples. A direct comparison of cooled and diluted soot with suspended and re-aerosolized soot, examined as a function of wavelength and particle size, would be required. Efforts are currently underway in our laboratory to perform such a study. It is not currently known whether the optical properties of size-selected particles are altered by this sampling process. Changes in mixing state and particle morphology are possible, and not currently constrained in this work. While previous work suggested that the effect of large, multiply charged particles was not likely significant for particle diameters $\geq 200 \mathrm{~nm}$ (a restriction followed in this work; Singh et al., 2014), this conclusion is limited to monodisperse aerosols. Adjustment of SSA due to large, multiply charged particles may have to be performed when there are significant changes in SSA as a function of particle size. The importance of this is partially due to the tight systematic uncertainty requirements of SSA measurements.

When samples were stored for more than a few weeks, differences in the extinction and scattering cross sections were observed. A statistical framework, previously developed by our group for analyzing polystyrene spheres (Singh et al., 2014), was applied to soot, and the error in SSA was found to be $3-6 \%$. This error was dominated by the truncation angle correction factor $C(\lambda)$. To reduce this error, it would be useful to rely on a scheme that does not depend on the Ångstrom scattering exponent, which does not well represent particle size at low SSA values. Instead, a method for correcting the nephelometer truncation angle error should be devised for submicron soot particles, since they consist of aggregates of glassy carbon spheres, tar balls, or a mixture of both. To perform this correction, particle size must be selected and the size distribution known.

SSA was determined for fresh BB soot using the extinction-minus-scattering method for a range of particle sizes $(300-500 \mathrm{~nm})$ and a wide range of wavelengths (500$660 \mathrm{~nm}$ ), which is wider than previous direct measurements of BB aerosols. This is important, since the accurate measurement of aerosol optical properties over the entire solar spectrum is a technological challenge that must be addressed to quantify the impact of aerosols on climate. The optical properties (extinction, scattering, and absorption cross sections; Ångstrom absorption exponent; and SSA) were measured for fresh particles produced from burning white pine, red oak, and cedar. The extinction, scattering, and absorption cross sections decreased slightly toward higher wavelengths, producing a nearly uniform value of SSA for each particle size and fuel source. SSA values ranged from 0.46 to 0.74. Results show that SSA is not uniformly greater for the 
smoldering stage than the flaming stage. This was especially true for $300 \mathrm{~nm}$ particles, but even for larger particles where the mean SSA for the smoldering stage was greater than the flaming stage, half did not exhibit statistically significant differences.

While SSA exhibited no wavelength dependence in this work, there was particle size dependence. SSA increased with particle diameter for smoldering fires, whereas flaming fires did not exhibit any trend as a function of particle size. This is likely due to changes in the contribution of tar-balllike spheres and fractal BC as a function of particle size. For radiative transfer models, it is inappropriate to assign a uniform SSA to all particle diameters, which are typically measured for the entire size distribution and integrated over both combustion stages.

In a comparison with literature values, white pine had an SSA that was $\sim 0.1$ larger than reported values, likely due to the cooking burner employed by Liu et al. (2014). In comparing different types of pine under similar burning conditions, significant differences in SSA (0.19-0.53) were observed between species. That is not to say that the MCE for these different species was identical or similar. Indeed, MCE was frequently either not measured or could not be inferred. However, it is likely that MCE varies with fuel type, and that these are not independent variables. The lack of SSA spectral dependence seen in this work is consistent with BB haze observations, though field observations of fresh soot typically had higher SSA values than those in this work. This lack of spectral dependence is consistent with $\mathrm{MCE}_{\mathrm{FI}}$ values of $<0.92$ (Liu et al., 2014). While MCE clearly influences SSA, SSA differences of $0.15-0.4$ or greater can be attributed to fuel type or fuel state for fresh soot. The relatively low SSA values, however, are consistent with $\mathrm{MCE}_{\mathrm{FI}}$ values of $>0.92$. A similar difficulty is found with $\mathrm{EC} /(\mathrm{EC}+\mathrm{OC})-$ based schemes (Pokhrel et al., 2016), though the cutoff is at 0.2 .

Despite the low SSA values observed in this work, AAE values were quite high (1.59-5.57). AAE was larger for the smoldering stage than for the flaming stage, which is consistent with the effects of a greater contribution of $\mathrm{BrC}$ in smoldering flames. For white pine and cedar, such large values of AAE are only observed when SSA is $>0.85$ at $532 \mathrm{~nm}$, which is inconsistent with our SSA measurements. When also considering issues with low SSA and a lack of SSA spectral dependence, this suggests that there are issues with the MCEbased framework of Liu et al. and the $\mathrm{EC} /(\mathrm{EC}+\mathrm{OC})$-based framework of Pokhrel at al.

Biomass burning is a major global phenomenon with an unusually large number of degrees of freedom, which include morphology, size distribution, mixing state, age, composition, concentration, location, flaming condition, fuel type, fuel state, humidity, and chemical oxidants. It is practically impossible to account for all sources of uncertainty, but not all degrees of freedom are equally important. The most significant effects on the intrinsic optical properties of fresh
BB particles (i.e., morphology and composition) seem to be burning stage, particle size, fuel type, and fuel condition (green, brown, mixed, litter, etc.). While this work investigates key parameters affecting fresh soot, the optical properties of aged particles are also significantly influenced by mixing state, humidity, and chemical processes.

Future work involves a plan to design and build an indoor chamber that will be connected directly to the output of a furnace, where additional gases of relevant organic compounds (or proxies of semivolatile species) and nitrogen oxides can be added to simulate atmospheric aging of the BB aerosols. This includes isoprene and many monoterpenes (like $\alpha$ - and $\beta$-pinene), common VOC oxidation products, $\mathrm{NO}$, and $\mathrm{NO}_{2}$, at concentrations that reflect the conditions observed during forest fires. The optical properties of BB particles in the chamber will be monitored as a function of composition and age. The relative quantities of EC and OC will be measured on filter samples, and $\mathrm{MCE}_{\mathrm{FI}}$ will be determined via $\mathrm{CO}$ and $\mathrm{CO}_{2}$ measurements. These chamber $\mathrm{CO}$ and $\mathrm{CO}_{2}$ measurements will also be important in controlling burning conditions so that they match $\mathrm{CO}$ and $\mathrm{CO}_{2}$ measurements observed during wildfires. Additionally, furnace conditions can be altered so that different burning states can be investigated. Since satellite measurements of SSA cannot distinguish between BB aerosols and other types of aerosols, controlled experiments that reflect natural conditions are needed to better assess the direct contribution of BB to climate forcing.

\section{Data availability}

The data used to generate Figs. 5-10 for SSA as a function of wavelength for cedar, red oak, and white pine for 300, 400, and $500 \mathrm{~nm}$ particles during the flaming stage and during the smoldering stage, and the data used to generate Figs. 11-12 for SSA as a function of size parameter are provided as an Excel file in the Supplement. The error analysis used in generating the data is described briefly in this paper, and more details are available in Singh et al. (2014).

\section{The Supplement related to this article is available online at doi:10.5194/acp-16-13491-2016-supplement.}

Author contributions. Sujeeta Singh ran all the experiments and analyzed the data. Marc N. Fiddler developed the data analysis software and designed the experiments. Solomon Bililign is the principal investigator of the project and supervised the work. 
Acknowledgements. This work is supported by the Department of Defense under grant no. W911NF-11-1-0188. We acknowledge the support from the Joint School of Nanoscience and Nanoengineering at NCA\&T for the use of the imaging facilities. The authors also acknowledge the contribution of Damon Smith in collecting field samples.

Edited by: P. Formenti

Reviewed by: two anonymous referees

\section{References}

Abo Riziq, A., Erlick, C., Dinar, E., and Rudich, Y.: Optical properties of absorbing and non-absorbing aerosols retrieved by cavity ring down (CRD) spectroscopy, Atmos. Chem. Phys., 7, 15231536, doi:10.5194/acp-7-1523-2007, 2007.

Abo Riziq, A., Trainic, M., Erlick, C., Segre, E., and Rudich, Y.: Extinction efficiencies of coated absorbing aerosols measured by cavity ring down aerosol spectrometry, Atmos. Chem. Phys., 8, 1823-1833, doi:10.5194/acp-8-1823-2008, 2008.

Alonso-Blanco, E., Calvo, A. I., Pont, V., Mallet, M., Fraile, R., and Castro, A.: Impact of biomass burning on aerosol size distribution, aerosol optical properties and associated radiative forcing, Aerosol Air Qual. Res., 14, 708-724, doi:10.4209/aaqr.2013.05.0163, 2014.

Anderson, T. L. and Ogren, J. A.: Determining aerosol radiative properties using the TSI 3563 integrating nephelometer, Aerosol Sci. Technol., 29, 57-69, doi:10.1080/02786829808965551, 1998.

Arnott, W., Moosmüller, H., Fred Rogers, C., Jin, T., and Bruch, R.: Photoacoustic spectrometer for measuring light absorption by aerosol: Instrument description, Atmos. Environ., 33, 28452852, doi:10.1016/S1352-2310(98)00361-6, 1999.

Arnott, W. P., Moosmüller, H., Sheridan, P. J., Ogren, J. A., Raspet, R., Slaton, W. V., Hand, J. L., Kreidenweis, S. M., and Collett, J. L., Jr.: Photoacoustic and filter-based ambient aerosol light absorption measurements: Instrument comparisons and the role of relative humidity, J. Geophys. Res.-Atmos., 108, 4034, doi:10.1029/2002jd002165, 2003.

Backman, J., Virkkula, A., Petäjä, T., Aurela, M., Frey, A., and Hillamo, R.: Impacts of volatilisation on light scattering and filter-based absorption measurements: a case study, Atmos. Meas. Tech., 3, 1205-1216, doi:10.5194/amt-3-1205-2010, 2010.

Bergstrom, R. W., Pilewskie, P., Schmid, B., and Russell, P. B.: Estimates of the spectral aerosol single scattering albedo and aerosol radiative effects during SAFARI 2000, J. Geophys. Res.-Atmos., 108, 8474, doi:10.1029/2002JD002435, 2003.

Beyersdorf, A.: Smoke optical fires sampled during SEAC 4 RS, NASA Langley LARGE and AVOCET Groups -PPT, Science Meeting, Studies of Emissions and Atmospheric Composition, Clouds and Climate Coupling by Regional Surveys (SEAC4RS), Boulder, Co, April 15-18, 2014, 2013.

Bond, T. C., Anderson, T. L., and Campbell, D.: Calibration and intercomparison of filter-based measurements of visible light absorption by aerosols, Aerosol Sci. Technol., 30, 582-600, doi:10.1080/027868299304435, 1999.
Bond, T. C. and Bergstrom, R. W.: Light absorption by carbonaceous particles: An investigative review, Aerosol Sci. Technol., 40, 27-67, doi:10.1080/02786820500421521, 2006.

Bond, T. C., Covert, D. S., and Müller, T.: Truncation and angular-scattering corrections for absorbing aerosol in the TSI 3563 Nephelometer, Aerosol Sci. Technol., 43, 866-871, doi:10.1080/02786820902998373, 2009.

Bond, T. C., Doherty, S. J., Fahey, D. W., Forster, P. M., Berntsen, T., DeAngelo, B. J., Flanner, M. G., Ghan, S., Kärcher, B., Koch, D., Kinne, S., Kondo, Y., Quinn, P. K., Sarofim, M. C., Schultz, M. G., Schulz, M., Venkataraman, C., Zhang, H., Zhang, S., Bellouin, N., Guttikunda, S. K., Hopke, P. K., Jacobson, M. Z., Kaiser, J. W., Klimont, Z., Lohmann, U., Schwarz, J. P., Shindell, D., Storelvmo, T., Warren, S. G., and Zender, C. S.: Bounding the role of black carbon in the climate system: A scientific assessment, J. Geophys. Res.-Atmos., 118, 5380-5552, doi:10.1002/jgrd.50171, 2013.

Butler, T. J. A., Miller, J. L., and Orr-Ewing, A. J.: Cavity ring-down spectroscopy measurements of single aerosol particle extinction. I. The effect of position of a particle within the laser beam on extinction, J. Chem. Phys., 126, 174-302, doi:10.1063/1.2723735, 2007.

Chakrabarty, R. K., Moosmüller, H., Chen, L.-W. A., Lewis, K., Arnott, W. P., Mazzoleni, C., Dubey, M. K., Wold, C. E., Hao, W. M., and Kreidenweis, S. M.: Brown carbon in tar balls from smoldering biomass combustion, Atmos. Chem. Phys., 10, 6363 6370, doi:10.5194/acp-10-6363-2010, 2010.

Chakrabarty, R. K., Beres, N. D., Moosmuller, H., China, S., Mazzoleni, C., Dubey, M. K., Liu, L., and Mishchenko, M. I.: Soot superaggregates from flaming wildfires and their direct radiative forcing, Sci. Rep., 4, 5508, doi:10.1038/srep05508, 2014.

Chang, J. L. and Thompson, J. E.: Characterization of colored products formed during irradiation of aqueous solutions containing $\mathrm{H}_{2} \mathrm{O}_{2}$ and phenolic compounds, Atmos. Environ., 44, 541-551, doi:10.1016/j.atmosenv.2009.10.042, 2010.

Chen, L. W. A., Moosmüller, H., Arnott, W. P., Chow, J. C., Watson, J. G., Susott, R. A., Babbitt, R. E., Wold, C. E., Lincoln, E. N., and Hao, W. M.: Particle emissions from laboratory combustion of wildland fuels: In situ optical and mass measurements, Geophys. Res. Lett., 33, L04803, doi:10.1029/2005GL024838, 2006.

Clarke, A. D., Shinozuka, Y., Kapustin, V. N., Howell, S., Huebert, B., Doherty, S., Anderson, T., Covert, D., Anderson, J., Hua, X., Moore II, K. G., McNaughton, C., Carmichael, G., and Weber, R.: Size distributions and mixtures of dust and black carbon aerosol in Asian outflow: Physiochemistry and optical properties, J. Geophys. Res.-Atmos., 109, D15S09, doi:10.1029/2003JD004378, 2004.

Cubison, M. J., Ortega, A. M., Hayes, P. L., Farmer, D. K., Day, D., Lechner, M. J., Brune, W. H., Apel, E., Diskin, G. S., Fisher, J. A., Fuelberg, H. E., Hecobian, A., Knapp, D. J., Mikoviny, T., Riemer, D., Sachse, G. W., Sessions, W., Weber, R. J., Weinheimer, A. J., Wisthaler, A., and Jimenez, J. L.: Effects of aging on organic aerosol from open biomass burning smoke in aircraft and laboratory studies, Atmos. Chem. Phys., 11, 12049-12064, doi:10.5194/acp-11-12049-2011, 2011.

Dinar, E., Riziq, A. A., Spindler, C., Erlick, C., Kiss, G., and Rudich, Y.: The complex refractive index of atmospheric and model humic-like substances (HULIS) retrieved by a cavity ring 
down aerosol spectrometer (CRD-AS), Faraday Discuss., 137, 279-295, doi:10.1039/b703111d, 2008.

Dusek, U., Frank, G. P., Hildebrandt, L., Curtius, J., Schneider, J., Walter, S., Chand, D., Drewnick, F., Hings, S., Jung, D., Borrmann, S., and Andreae, M. O.: Size matters more than chemistry for cloud-nucleating ability of aerosol particles, Science, 312, 1375-1378, doi:10.1126/science.1125261, 2006.

Eck, T. F., Holben, B. N., Reid, J. S., O’Neill, N. T., Schafer, J. S., Dubovik, O., Smirnov, A., Yamasoe, M. A., and Artaxo, P.: High aerosol optical depth biomass burning events: A comparison of optical properties for different source regions, Geophys. Res. Lett., 30, 2035, doi:10.1029/2003g1017861, 2003.

Flowers, B. A., Dubey, M. K., Mazzoleni, C., Stone, E. A., Schauer, J. J., Kim, S.-W., and Yoon, S. C.: Optical-chemicalmicrophysical relationships and closure studies for mixed carbonaceous aerosols observed at Jeju Island; 3-laser photoacoustic spectrometer, particle sizing, and filter analysis, Atmos. Chem. Phys., 10, 10387-10398, doi:10.5194/acp-10-10387-2010, 2010.

Fu, J. S., Hsu, N. C., Gao, Y., Huang, K., Li, C., Lin, N.-H., and Tsay, S.-C.: Evaluating the influences of biomass burning during 2006 BASE-ASIA: a regional chemical transport modeling, Atmos. Chem. Phys., 12, 3837-3855, doi:10.5194/acp-12-38372012, 2012.

Grinshpun, S. A., Willeke, K., Ulevicius, V., Juozaitis, A., Terzieva, S., Donnelly, J., Stelma, G. N., and Brenner, K. P.: Effect of impaction, bounce and reaerosolization on the collection efficiency of impingers, Aerosol Sci. Technol., 26, 326-342, doi:10.1080/02786829708965434, 1997.

Gyawali, M., Arnott, W. P., Lewis, K., and Moosmüller, H.: In situ aerosol optics in Reno, NV, USA during and after the summer 2008 California wildfires and the influence of absorbing and non-absorbing organic coatings on spectral light absorption, Atmos. Chem. Phys., 9, 8007-8015, doi:10.5194/acp-9-8007-2009, 2009

Gyawali, M., Arnott, W. P., Zaveri, R. A., Song, C., Moosmüller, H., Liu, L., Mishchenko, M. I., Chen, L.-W. A., Green, M. C., Watson, J. G., and Chow, J. C.: Photoacoustic optical properties at UV, VIS, and near IR wavelengths for laboratory generated and winter time ambient urban aerosols, Atmos. Chem. Phys., 12, 2587-2601, doi:10.5194/acp-12-2587-2012, 2012.

Haan, D. O. D., Brauers, T., Oum, K., Stutz, J., Nordmeyer, T., and Finlayson-Pitts, B. J.: Heterogeneous chemistry in the troposphere: Experimental approaches and applications to the chemistry of sea salt particles, Int. Rev. Phys. Chem., 18, 343-385, 10.1080/014423599229910, 1999.

Habib, G., Venkataraman, C., Bond, T. C., and Schauer, J. J.: Chemical, microphysical and optical properties of primary particles from the combustion of biomass fuels, Environ. Sci. Technol., 42, 8829-8834, doi:10.1021/es800943f, 2008.

Hallar, A. G., Strawa, A. W., Schmid, B., Andrews, E., Ogren, J., Sheridan, P., Ferrare, R., Covert, D., Elleman, R., Jonsson, H., Bokarius, K., and Luu, A.: Atmospheric radiation measurements aerosol intensive operating period: Comparison of aerosol scattering during coordinated flights, J. Geophys. Res.-Atmos., 111, D05S09, doi:10.1029/2005jd006250, 2006.

Haywood, J. M., Osborne, S. R., Francis, P. N., Keil, A., Formenti, P., Andreae, M. O., and Kaye, P. H.: The mean physical and optical properties of regional haze dominated by biomass burning aerosol measured from the C-130 aircraft during SAFARI 2000, J. Geophys. Res.-Atmos., 108, 8473 , doi:10.1029/2002JD002226, 2003.

Haywood, J. M., Pelon, J., Formenti, P., Bharmal, N., Brooks, M., Capes, G., Chazette, P., Chou, C., Christopher, S., Coe, H., Cuesta, J., Derimian, Y., Desboeufs, K., Greed, G., Harrison, M., Heese, B., Highwood, E. J., Johnson, B., Mallet, M., Marticorena, B., Marsham, J., Milton, S., Myhre, G., Osborne, S. R., Parker, D. J., Rajot, J. L., Schulz, M., Slingo, A., Tanré, D., and Tulet, P.: Overview of the dust and biomass-burning experiment and african monsoon multidisciplinary analysis special observing period-0, J. Geophys. Res.-Atmos., 113, D00C17, doi:10.1029/2008JD010077, 2008.

He, C., Liou, K.-N., Takano, Y., Zhang, R., Levy Zamora, M., Yang, P., Li, Q., and Leung, L. R.: Variation of the radiative properties during black carbon aging: theoretical and experimental intercomparison, Atmos. Chem. Phys., 15, 11967-11980, doi:10.5194/acp-15-11967-2015, 2015.

Hemminger, J. C.: Heterogeneous chemistry in the troposphere: A modern surface chemistry approach to the study of fundamental processes, Int. Rev. Phys. Chem., 18, 387-417, doi:10.1080/014423599229929, 1999.

Hennigan, C. J., Miracolo, M. A., Engelhart, G. J., May, A. A., Presto, A. A., Lee, T., Sullivan, A. P., McMeeking, G. R., Coe, H., Wold, C. E., Hao, W.-M., Gilman, J. B., Kuster, W. C., de Gouw, J., Schichtel, B. A., Collett Jr., J. L., Kreidenweis, S. M., and Robinson, A. L.: Chemical and physical transformations of organic aerosol from the photo-oxidation of open biomass burning emissions in an environmental chamber, Atmos. Chem. Phys., 11, 7669-7686, doi:10.5194/acp-11-7669-2011, 2011.

Holben, B. N., Eck, T. F., Slutsker, I., Tanré, D., Buis, J. P., Setzer, A., Vermote, E., Reagan, J. A., Kaufman, Y. J., Nakajima, T., Lavenu, F., Jankowiak, I., and Smirnov, A.: AERONET - A federated instrument network and data archive for aerosol characterization, Remote Sens. Environ., 66, 1-16, doi:10.1016/S0034 4257(98)00031-5, 1998.

Hopkins, R. J., Lewis, K., Desyaterik, Y., Wang, Z., Tivanski, A. V., Arnott, W. P., Laskin, A., and Gilles, M. K.: Correlations between optical, chemical and physical properties of biomass burn aerosols, Geophys. Res. Lett., 34, L18806, doi:10.1029/2007GL030502, 2007.

IPCC: Climate Change 2013: The Physical Science Basis. Contribution of Working Group I to the Fifth Assessment Report of the Intergovernmental Panel on Climate Change, Intergovernmental Panel on Climate Change, Cambridge, UK, 1535, 2013.

Jacobson, M. Z.: A physically-based treatment of elemental carbon optics: Implications for global direct forcing of aerosols, Geophys. Res. Lett., 27, 217-220, doi:10.1029/1999GL010968, 2000 .

Jacobson, M. Z.: Effects of biomass burning on climate, accounting for heat and moisture fluxes, black and brown carbon, and cloud absorption effects, J. Geophys. Res.-Atmos., 119, 8980 9002, doi:10.1002/2014JD021861, 2014.

Johnson, B. T., Osborne, S. R., Haywood, J. M., and Harrison, M. A. J.: Aircraft measurements of biomass burning aerosol over West Africa during DABEX, J. Geophys. Res.-Atmos., 113, D00C06, doi:10.1029/2007JD009451, 2008.

Khalizov, A. F., Xue, H., Wang, L., Zheng, J., and Zhang, R.: Enhanced light absorption and scattering by carbon soot aerosol in- 
ternally mixed with sulfuric acid, J. Phys. Chem. A, 113, 10661074, doi:10.1021/jp807531n, 2009a.

Khalizov, A. F., Zhang, R., Zhang, D., Xue, H., Pagels, J., and McMurry, P. H.: Formation of highly hygroscopic soot aerosols upon internal mixing with sulfuric acid vapor, J. Geophys. ResAtmos., 114, D05208, doi:10.1029/2008JD010595, 2009b.

Lack, D. A., Lovejoy, E. R., Baynard, T., Pettersson, A., and Ravishankara, A. R.: Aerosol absorption measurement using photoacoustic spectroscopy: Sensitivity, calibration, and uncertainty developments, Aerosol Sci. Technol., 40, 697-708, doi:10.1080/02786820600803917, 2006.

Lack, D. A., Langridge, J. M., Bahreini, R., Cappa, C. D., Middlebrook, A. M., and Schwarz, J. P.: Brown carbon and internal mixing in biomass burning particles, P. Natl. Acad. Sci. USA, 109, 14802-14807, doi:10.1073/pnas.1206575109, 2012.

Lewis, K., Arnott, W. P., Moosmüller, H., and Wold, C. E.: Strong spectral variation of biomass smoke light absorption and single scattering albedo observed with a novel dual-wavelength photoacoustic instruments, J. Geophys. Res.-Atmos., 113, D16203, doi:10.1029/2007JD009699, 2008.

Lin, N.-H., Tsay, S.-C., Maring, H. B., Yen, M.-C., Sheu, G.-R., Wang, S.-H., Chi, K. H., Chuang, M.-T., Ou-Yang, C.-F., Fu, J. S., Reid, J. S., Lee, C.-T., Wang, L.-C., Wang, J.-L., Hsu, C. N., Sayer, A. M., Holben, B. N., Chu, Y.-C., Nguyen, X. A., Sopajaree, K., Chen, S.-J., Cheng, M.-T., Tsuang, B.-J., Tsai, C.J., Peng, C.-M., Schnell, R. C., Conway, T., Chang, C.-T., Lin, K.-S., Tsai, Y. I., Lee, W.-J., Chang, S.-C., Liu, J.-J., Chiang, W.-L., Huang, S.-J., Lin, T.-H., and Liu, G.-R.: An overview of regional experiments on biomass burning aerosols and related pollutants in Southeast Asia: From BASE-ASIA and the Dongsha Experiment to 7-SEAS, Atmos. Environ., 78, 1-19, doi:10.1016/j.atmosenv.2013.04.066, 2013.

Lin, X., Willeke, K., Ulevicius, V., and Grinshpun, S. A.: Effect of sampling time on the collection efficiency of allglass impingers, Am. Ind. Hyg. Assoc. J., 58, 480-488, doi:10.1080/15428119791012577, 1997.

Liu, S., Aiken, A. C., Arata, C., Dubey, M. K., Stockwell, C. E., Yokelson, R. J., Stone, E. A., Jayarathne, T., Robinson, A. L., DeMott, P. J., and Kreidenweis, S. M.: Aerosol single scattering albedo dependence on biomass combustion efficiency: Laboratory and field studies, Geophys. Res. Lett., 41, 742-748, doi:10.1002/2013GL058392, 2014.

Mack, L. A., Levin, E. J. T., Kreidenweis, S. M., Obrist, D., Moosmüller, H., Lewis, K. A., Arnott, W. P., McMeeking, G. R., Sullivan, A. P., Wold, C. E., Hao, W.-M., Collett Jr., J. L., and Malm, W. C.: Optical closure experiments for biomass smoke aerosols, Atmos. Chem. Phys., 10, 9017-9026, doi:10.5194/acp-10-90172010, 2010.

Massoli, P., Murphy, D. M., Lack, D. A., Baynard, T., Brock, C. A., and Lovejoy, E. R.: Uncertainty in light scattering measurements by TSI Nephelometer: Results from laboratory studies and implications for ambient measurements, Aerosol Sci. Technol., 42, 1064-1074, doi:10.1080/02786820903156542, 2009.

McMeeking, G.: The optical, chemical, and physical properties of aerosols and gases emitted by the laboratory combustion of wildland fuels, Department of Atmospheric Science, Colorado State University, Fort Collins, Colorado, 2008.

Mellon, D., King, S., Kim, J., Reid, J. P., and Orr-Ewing, A. J.: Measurements of extinction by aerosol particles in the near-infrared using continuous wave cavity ring-down spectroscopy, J. Phys. Chem. A, 115, 774-783, doi:10.1021/jp109894x, 2011.

Miljevic, B., Surawski, N. C., Bostrom, T., and Ristovski, Z. D.: Restructuring of carbonaceous particles upon exposure to organic and water vapours, J. Aerosol Sci., 47, 48-57, doi:10.1016/j.jaerosci.2011.12.005, 2012.

Miller, J. L. and Orr-Ewing, A. J.: Cavity ring-down spectroscopy measurement of single aerosol particle extinction, II. Extinction of light by an aerosol particle in an optical cavity excited by a cw laser, J. Chem. Phys., 126, doi:10.1063/1.2723736, 2007.

Moosmüller, H., Chakrabarty, R. K., and Arnott, W. P.: Aerosol light absorption and its measurement: A review, J. Quant. Spectrosc. Ra., 110, 844-878, doi:10.1016/j.jqsrt.2009.02.035, 2009.

Nakayama, T., Sato, K., Matsumi, Y., Imamura, T., Yamazaki, A., and Uchiyama, A.: Wavelength and NOx dependent complex refractive index of SOAs generated from the photooxidation of toluene, Atmos. Chem. Phys., 13, 531-545, doi:10.5194/acp-13531-2013, 2013.

Nussbaumer, T.: Overview on technologies for biomass combustion and emission levels of particulate matter, Swiss Federal Office for the Environment (FOEN), Zürich, Switzerland, 2010.

Pettersson, A., Lovejoy, E. R., Brock, C. A., Brown, S. S., and Ravishankara, A. R.: Measurement of aerosol optical extinction at 532nm with pulsed cavity ring down spectroscopy, J. Aerosol Sci., 35, 995-1011, doi:10.1016/j.jaerosci.2004.02.008, 2004.

Petzold, A. and Schonlinner, M.: Multi-angle absorption photometry - A new method for the measurement of aerosol light absorption and atmospheric black carbon, J. Aerosol Sci., 35, 421-441, doi:10.1016/j.jaerosci.2003.09.005, 2004.

Pokhrel, R. P., Wagner, N. L., Langridge, J. M., Lack, D. A., Jayarathne, T., Stone, E. A., Stockwell, C. E., Yokelson, R. J., and Murphy, S. M.: Parameterization of single-scattering albedo (SSA) and absorption Ångström exponent (AAE) with EC / OC for aerosol emissions from biomass burning, Atmos. Chem. Phys., 16, 9549-9561, doi:10.5194/acp-16-9549-2016, 2016.

Radney, J. G., Ma, X., Gillis, K. A., Zachariah, M. R., Hodges, J. T., and Zangmeister, C. D.: Direct measurements of mass-specific optical cross sections of single-component aerosol mixtures, Anal. Chem., 85, 8319-8325, doi:10.1021/ac401645y, 2013.

Radney, J. G., You, R., Ma, X., Conny, J. M., Zachariah, M. R., Hodges, J. T., and Zangmeister, C. D.: Dependence of soot optical properties on particle morphology: Measurements and model comparisons, Environ. Sci. Technol., 48, 3169-3176, doi:10.1021/es4041804, 2014.

Ramanathan, V. and Carmichael, G.: Global and regional climate changes due to black carbon, Nat. Geosci., 1, 221-227, doi:10.1038/ngeo156, 2008.

Reid, J. S., Koppmann, R., Eck, T. F., and Eleuterio, D. P.: A review of biomass burning emissions part II: intensive physical properties of biomass burning particles, Atmos. Chem. Phys., 5, 799825, doi:10.5194/acp-5-799-2005, 2005.

Reid, J. S., Hyer, E. J., Johnson, R. S., Holben, B. N., Yokelson, R. J., Zhang, J., Campbell, J. R., Christopher, S. A., Di Girolamo, L., Giglio, L., Holz, R. E., Kearney, C., Miettinen, J., Reid, E. A., Turk, F. J., Wang, J., Xian, P., Zhao, G., Balasubramanian, R., Chew, B. N., Janjai, S., Lagrosas, N., Lestari, P., Lin, N.H., Mahmud, M., Nguyen, A. X., Norris, B., Oanh, N. T. K., Oo, M., Salinas, S. V., Welton, E. J., and Liew, S. C.: Observing and understanding the Southeast Asian aerosol system by remote 
sensing: An initial review and analysis for the Seven Southeast Asian Studies (7SEAS) program, Atmos. Res., 122, 403-468, doi:10.1016/j.atmosres.2012.06.005, 2013.

Reponen, T., Willeke, K., Grinshpun, S. A., and Nevalainen, A.: Biological Particle Sampling, in: Aerosol Measurement: Principles, Techniques, and Applications, 3rd Edn., edited by: Kulkarni, P., Baron, P. A., and Willeke, K., John Wiley \& Sons, Inc., Hoboken, New Jersey, 549-570, 2011.

Robinson, A. L., Donahue, N. M., Shrivastava, M. K., Weitkamp, E. A., Sage, A. M., Grieshop, A. P., Lane, T. E., Pierce, J. R., and Pandis, S. N.: Rethinking organic aerosols: Semivolatile emissions and photochemical aging, Science, 315, 1259-1262, doi:10.1126/science.1133061, 2007.

Rudich, Y., Donahue, N. M., and Mentel, T. F.: Aging of organic aerosol: Bridging the gap between laboratory and field studies, Annu. Rev. Phys. Chem., 58, 321-352, doi:10.1146/annurev.physchem.58.032806.104432, 2007.

Saleh, R., Hennigan, C. J., McMeeking, G. R., Chuang, W. K., Robinson, E. S., Coe, H., Donahue, N. M., and Robinson, A. L.: Absorptivity of brown carbon in fresh and photo-chemically aged biomass-burning emissions, Atmos. Chem. Phys., 13, 76837693, doi:10.5194/acp-13-7683-2013, 2013.

Schnaiter, M., Linke, C., Möhler, O., Naumann, K. H., Saathoff, H., Wagner, R., Schurath, U., and Wehner, B.: Absorption amplification of black carbon internally mixed with secondary organic aerosol, J. Geophys. Res.-Atmos., 110, D19204, doi:10.1029/2005JD006046, 2005a.

Schnaiter, M., Schmid, O., Petzold, A., Fritzsche, L., Klein, K. F., Andreae, M. O., Helas, G., Thielmann, A., Gimmler, M., Möhler, O., Linke, C., and Schurath, U.: Measurement of wavelength-resolved light absorption by aerosols utilizing a UV-VIS extinction cell, Aerosol Sci. Technol., 39, 249-260, doi:10.1080/027868290925958, 2005b.

Schnaiter, M., Gimmler, M., Llamas, I., Linke, C., Jäger, C., and Mutschke, H.: Strong spectral dependence of light absorption by organic carbon particles formed by propane combustion, Atmos. Chem. Phys., 6, 2981-2990, doi:10.5194/acp-6-2981-2006, 2006.

Schwarz, J. P., Spackman, J. R., Fahey, D. W., Gao, R. S., Lohmann, U., Stier, P., Watts, L. A., Thomson, D. S., Lack, D. A., Pfister, L., Mahoney, M. J., Baumgardner, D., Wilson, J. C., and Reeves, J. M.: Coatings and their enhancement of black carbon light absorption in the tropical atmosphere, J. Geophys. Res.-Atmos., 113, D03203, doi:10.1029/2007JD009042, 2008.

Singh, S., Fiddler, M. N., Smith, D., and Bililign, S.: Error analysis and uncertainty in the determination of aerosol optical properties using cavity ring-down spectroscopy, integrating nephelometry, and the extinction-minus-scattering method, Aerosol Sci. Technol., 48, 1345-1359, doi:10.1080/02786826.2014.984062, 2014.

Smith, J. D. and Atkinson, D. B.: A portable pulsed cavity ring-down transmissometer for measurement of the optical extinction of the atmospheric aerosol, Analyst, 126, 1216-1220, doi:10.1039/b101491i, 2001.

Spindler, C., Riziq, A. A., and Rudich, Y.: Retrieval of aerosol complex refractive index by combining cavity ring down aerosol spectrometer measurements with full size distribution information, Aerosol Sci. Technol., 41, 1011-1017, doi:10.1080/02786820701682087, 2007.
Strawa, A. W., Castaneda, R., Owano, T., Baer, D. S., and Paldus, B. A.: The measurement of aerosol optical properties using continuous wave cavity ring-down techniques, J. Atmos. Ocean. Technol., 20, 454-465, 2003.

Tumolva, L., Park, J.-Y., Kim, J.-s., Miller, A. L., Chow, J. C., Watson, J. G., and Park, K.: Morphological and elemental classification of freshly emitted soot particles and atmospheric ultrafine particles using the TEM/EDS, Aerosol Sci. Technol., 44, 202 215, doi:10.1080/02786820903518907, 2010.

Uin, J., Tamm, E., and Mirme, A.: Very long DMA for the Generation of the calibration aerosols in particle diameter range up to $10 \mu \mathrm{m}$ by electrical separation, Aerosol Air Qual. Res., 11, 531538, doi:10.4209/aaqr.2011.05.0068, 2011.

Vakkari, V., Kerminen, V.-M., Beukes, J. P., Tiitta, P., van Zyl, P. G., Josipovic, M., Venter, A. D., Jaars, K., Worsnop, D. R., Kulmala, M., and Laakso, L.: Rapid changes in biomass burning aerosols by atmospheric oxidation, Geophys. Res. Lett., 41, 2644-2651, doi:10.1002/2014GL059396, 2014

Wang, Q., Huang, R. J., Cao, J., Han, Y., Wang, G., Li, G., Wang, Y., Dai, W., Zhang, R., and Zhou, Y.: Mixing state of black carbon aerosol in a heavily polluted urban area of china: Implications for light absorption enhancement, Aerosol Sci. Technol., 48, 689697, doi:10.1080/02786826.2014.917758, 2014.

Wei, Y., Ma, L., Cao, T., Zhang, Q., Wu, J., Buseck, P. R., and Thompson, J. E.: Light scattering and extinction measurements combined with laser-induced incandescence for the real-time determination of soot mass absorption cross section, Anal. Chem., 85, 9181-9188, doi:10.1021/ac401901b, 2013.

Wiedensohler, A.: An approximation of the bipolar charge distribution for particles in the submicron size range, J. Aerosol Sci., 19, 387-389, doi:10.1016/0021-8502(88)90278-9, 1988.

Yen, M.-C., Peng, C.-M., Chen, T.-C., Chen, C.-S., Lin, N.-H., Tzeng, R.-Y., Lee, Y.-A., and Lin, C.-C.: Climate and weather characteristics in association with the active fires in northern Southeast Asia and spring air pollution in Taiwan during 2010 7-SEAS/Dongsha Experiment, Atmos. Environ., 78, 3550, doi:10.1016/j.atmosenv.2012.11.015, 2013.

Yokelson, R. J., Crounse, J. D., DeCarlo, P. F., Karl, T., Urbanski, S., Atlas, E., Campos, T., Shinozuka, Y., Kapustin, V., Clarke, A. D., Weinheimer, A., Knapp, D. J., Montzka, D. D., Holloway, J., Weibring, P., Flocke, F., Zheng, W., Toohey, D., Wennberg, P. O., Wiedinmyer, C., Mauldin, L., Fried, A., Richter, D., Walega, J., Jimenez, J. L., Adachi, K., Buseck, P. R., Hall, S. R., and Shetter, R.: Emissions from biomass burning in the Yucatan, Atmos. Chem. Phys., 9, 5785-5812, doi:10.5194/acp-9-5785-2009, 2009.

Zhang, R., Khalizov, A. F., Pagels, J., Zhang, D., Xue, H., and McMurry, P. H.: Variability in morphology, hygroscopicity, and optical properties of soot aerosols during atmospheric processing, P. Natl. Acad. Sci. USA, 105, 10291-10296, doi:10.1073/pnas.0804860105, 2008. 